\title{
Thalamocortical Long-Term Potentiation Becomes Gated after the Early Critical Period in the Auditory Cortex
}

\author{
Sungkun Chun, Ildar T. Bayazitov, Jay A. Blundon, and Stanislav S. Zakharenko \\ Department of Developmental Neurobiology, St. Jude Children's Research Hospital, Memphis, Tennessee 38105
}

Cortical maps in sensory cortices are plastic, changing in response to sensory experience. The cellular site of such plasticity is currently debated. Thalamocortical (TC) projections deliver sensory information to sensory cortices. TC synapses are currently dismissed as a locus of cortical map plasticity because TC synaptic plasticity is thought to be limited to neonates, whereas cortical map plasticity can be induced in both neonates and adults. However, in the auditory cortex ( $\mathrm{ACx}$ ) of adults, cortical map plasticity can be induced if animals attend to a sound or receive sounds paired with activation of cholinergic inputs from the nucleus basalis. We now show that, in the ACx, long-term potentiation (LTP), a major form of synaptic plasticity, is expressed at TC synapses in both young and mature mice but becomes gated with age. Using single-cell electrophysiology, two-photon glutamate uncaging, and optogenetics in TC slices containing the auditory thalamus and ACx, we show that TC LTP is expressed postsynaptically and depends on group I metabotropic glutamate receptors. TC LTP in mature ACx can be unmasked by cortical disinhibition combined with activation of cholinergic inputs from the nucleus basalis. Cholinergic inputs passing through the thalamic radiation activate $M_{1}$ muscarinic receptors on TC projections and sustain glutamate release at TC synapses via negative regulation of presynaptic adenosine signaling through $\mathrm{A}_{1}$ adenosine receptors. These data indicate that TC LTP in the ACx persists throughout life and therefore can potentially contribute to experience-dependent cortical map plasticity in the ACx in both young and adult animals.

\section{Introduction}

Sensory experiences have a long-lasting effect on the representation of information in sensory cortices. The learning of behaviorally important acoustic information can produce a change in the area of frequency representations within cortical maps in the auditory cortex (ACx) (Bakin and Weinberger, 1990; Recanzone et al., 1993; Buonomano and Merzenich, 1998; Gilbert, 1998; Fritz et al., 2003; Suga and Ma, 2003; Weinberger, 2004; Rutkowski and Weinberger, 2005). The enlarged cortical map region invariably corresponds to the trained sensory input (Recanzone et al., 1993; Gilbert et al., 2001; Rutkowski and Weinberger, 2005; Polley et al., 2006; Fahle, 2009; Bieszczad and Weinberger, 2010; Roelfsema et al., 2010) and is thought to reflect perceptual learning (Rutkowski and Weinberger, 2005; Polley et al., 2006; Weinberger, 2007; Bieszczad and Weinberger, 2010; Reed et al., 2011).

It has been suggested that long-term synaptic plasticity mechanisms underlie cortical map plasticity (Feldman et al., 1999; Fox, 2002; Feldman and Brecht, 2005), but the cellular locus of such

Received Aug. 9, 2012; revised Feb. 27, 2013; accepted March 13, 2013.

Author contributions: S.S.Z. designed research; S.C., I.T.B., and J.A.B. performed research; S.C., I.T.B., and J.A.B. analyzed data; J.A.B. and S.S.Z. wrote the paper.

This work was supported in part by National Institute of Mental Health Grants R01 MH079079 and R01 MH095810 and the American Lebanese Syrian Associated Charities. We thank Dr. Angela MacArthur for help in editing this manuscript. We also thank Drs. Troy Hackett, Michael Kilgard, Daniel Polley, and members of the Zakharenko laboratory for their constructive comments on previous versions of this manuscript.

The authors declare no competing financial interests.

Correspondence should be addressed to Dr. Stanislav Zakharenko, Department of Developmental Neurobiology, MS 323, St. Jude Children's Research Hospital, 262 Danny Thomas Place, Memphis, TN 38105-3678. E-mail: stanislav.zakharenko@stjude.org.

DOI:10.1523/JNEUROSCI.4500-12.2013

Copyright $\odot 2013$ the authors $\quad 0270-6474 / 13 / 337345-13 \$ 15.00 / 0$ plasticity is under debate. Sensory information reaches sensory cortices through thalamocortical (TC) projections, but synaptic plasticity at TC synapses is currently dismissed as a cellular locus of cortical map plasticity attributable to a disconnect between the age dependency of TC synaptic plasticity and that of cortical map plasticity. In rodents, cortical map plasticity can be induced in the ACx throughout the lifespan. In neonates, cortical plasticity can be induced by enriching the environment with a single tone (Zhang et al., 2001; de Villers-Sidani et al., 2007; Insanally et al., 2009; Dorrn et al., 2010). Similarly, long-term potentiation (LTP) and long-term depression (LTD) can be induced at TC synapses in brain slices by electrical stimulation of thalamic projections but only during an early critical period that corresponds to the first several postnatal days in rodents (Crair and Malenka, 1995; Barth and Malenka, 2001). However, in mature rodents, unattended or passive exposure to sounds has little plastic consequence for the ACx (Bakin and Weinberger, 1996; Bao et al., 2001; Polley et al., 2004). Cortical modifications in mature animals require that an acoustic stimulus be behaviorally relevant (Weinberger, 1995; Buonomano and Merzenich, 1998; Dahmen and King, 2007; Keuroghlian and Knudsen, 2007) or be paired with the activation of sources of modulatory, mainly cholinergic, inputs (Bakin and Weinberger, 1996; Kilgard and Merzenich, 1998; Ma and Suga, 2005). Similarly, it has been well documented that TC LTP and TC LTD cannot be induced in slices taken from rodents older than 2-3 weeks (Crair and Malenka, 1995; Kirkwood et al., 1995; Isaac et al., 1997; Feldman et al., 1998; Barth and Malenka, 2001; Foeller and Feldman, 2004; Daw et al., 2007b; Jiang et al., 2007).

The notion of a critical period for synaptic plasticity proposes that, on maturation, TC LTP and TC LTD are lost and cannot be 
a mechanism underlying experience-dependent cortical plasticity in sensory cortices. Recently, we found that a major form of synaptic plasticity, LTD, is not lost at TC synapses after the critical period but rather becomes gated. We found that TC LTD persists at TC synapses in the ACx far beyond the critical period on activation of presynaptic $M_{1}$ cholinergic receptors $\left(M_{1} R s\right)$ on thalamic inputs in the ACx (Blundon et al., 2011).

Because cortical map plasticity can be bidirectional (Weinberger, 1995; Polley et al., 1999; David et al., 2012), we hypothesized that TC LTP also exists in the mature ACx and is also gated. Here we report that LTP does persist at TC synapses long after the end of the critical period and becomes gated in mature ACx. We determined that TC LTP in the ACx is expressed postsynaptically, depends on group I mGluRs, and is gated by two independent mechanisms. Release of these gating mechanisms can be achieved by cortical disinhibition and activation of cholinergic projections from the nucleus basalis (NB). These results indicate that TC synapses do not lose their ability for bidirectional long-term synaptic plasticity even after the critical period and therefore may potentially be a substrate of cortical map plasticity in the ACx.

\section{Materials and Methods}

Animals and agents. Male C57BL/6J mice (The Jackson Laboratory), mice expressing cre recombinase in cholinergic neurons (ChAT-cre mice, stock number 006410; The Jackson Laboratory), and $A_{1} R^{-1-}$ mice (Johansson et al., 2001) of both sexes were used in all experiments. ChATcre and $A_{1} R^{-1-}$ mice were backcrossed to the C57BL/6J background for at least seven generations. In most experiments, we used mice that were substantially older than the early critical period for LTP. Mouse ages ranged between postnatal day 42 (P42) and P56. In some experiments, we used neonate mice at ages that correspond to the early critical period for LTP (P5-P7). The care and use of animals were reviewed and approved by the Institutional Animal Care and Use Committee of St. Jude Children's Research Hospital. Drugs were purchased from Tocris Bioscience.

Brain slice preparation. Acute primary TC slices $(400 \mu \mathrm{m})$ containing the $\mathrm{ACx}$ and portions of the ventral part of the medial geniculate nuclei (MGv) of the thalamus were prepared as described previously (Cruikshank et al., 2002; Richardson et al., 2009). Briefly, mouse brains were quickly removed and placed in cold $\left(4^{\circ} \mathrm{C}\right)$ dissecting artificial CSF (ACSF) containing $125 \mathrm{~mm}$ choline- $\mathrm{Cl}, 2.5 \mathrm{~mm} \mathrm{KCl}, 0.4 \mathrm{~mm} \mathrm{CaCl}_{2}, 6 \mathrm{~mm}$ $\mathrm{MgCl}_{2}, 1.25 \mathrm{~mm} \mathrm{NaH}_{2} \mathrm{PO}_{4}, 26 \mathrm{~mm} \mathrm{NaHCO}_{3}$, and $20 \mathrm{~mm}$ glucose (300$310 \mathrm{mOsm}$ ), with $95 \% \mathrm{O}_{2} / 5 \% \mathrm{CO}_{2}$. Primary TC slices were obtained from the left hemisphere by using a slicing angle of $15^{\circ}$. After $1 \mathrm{~h}$ of incubation in ACSF [ $125 \mathrm{~mm} \mathrm{NaCl}, 2.5 \mathrm{~mm} \mathrm{KCl}, 2 \mathrm{~mm} \mathrm{CaCl}_{2}, 2 \mathrm{~mm}$ $\mathrm{MgCl}_{2}$ ( $1 \mathrm{mM} \mathrm{MgCl}_{2}$ in pairing experiments), $1.25 \mathrm{~mm} \mathrm{NaH}_{2} \mathrm{PO}_{4}, 26 \mathrm{~mm}$ $\mathrm{NaHCO}_{3}$, and $20 \mathrm{~mm}$ glucose (300-310 mOsm), with $95 \% \mathrm{O}_{2} / 5 \% \mathrm{CO}_{2}$ ] at room temperature, the slices were transferred into the recording chamber and superfused $(2-3 \mathrm{ml} / \mathrm{min})$ with warm $\left(30-32^{\circ} \mathrm{C}\right)$ ACSF.

Whole-cell electrophysiology. Whole-cell recordings were obtained from cell bodies of layer III/IV thalamorecipient neurons in the ACx. Cell bodies of these neurons were found within the first $30-50 \%$ of the slice from the pial surface $(\sim 300-500 \mu \mathrm{m}$ from the pial surface). In most experiments, patch pipettes (open pipette resistance, 3.5-5 M $\Omega$ ) were filled with an internal solution containing $125 \mathrm{~mm} \mathrm{CsMeSO}_{3}, 2 \mathrm{~mm} \mathrm{CsCl}$, 10 mм HEPES, 0.1 mм EGTA, 4 mм MgATP, 0.3 mm NaGTP, $10 \mathrm{~mm} \mathrm{Na}_{2}$ creatine phosphate, $5 \mathrm{~mm}$ QX-314, $5 \mathrm{~mm}$ tetraethylammonium $\mathrm{Cl}$, and 10-25 $\mu$ M Alexa Fluor 594 ( $\mathrm{pH} 7.4$ was adjusted with $\mathrm{CsOH}, 290-295$ mOsm). QX-314 was included to block the generation of action potentials in recorded neurons. In pairing experiments, patch pipettes were filled with an internal solution containing $117.5 \mathrm{~mm}$ Cs gluconate, 17.5 mм CsCl, 8 mм NaCl, 10 mм HEPES, 0.2 mм EGTA, 4 mм MgATP, 0.3 mM NaGTP, pH 7.2 (280-290 mOsm) according to the previously published protocol (Crair and Malenka, 1995). Alexa Fluor 594 was added for visualization of dendritic structures during all experiments. Only neurons with dendritic spines (indicative of excitatory neurons) and a well-established primary apical dendrite extending to the pial surface (indicative of pyramidal neurons) were chosen. Neurons with any sign of dendritic damage were excluded from analysis.

Voltage-clamp recordings were made using a Multiclamp 700B (Molecular Devices), digitized (10 kHz; DigiData 1440A; Molecular Devices), and recorded using pClamp 10.0 software (Molecular Devices). EPSCs were recorded at holding membrane potentials of $-70 \mathrm{mV}$. IPSCs were recorded concomitantly with EPSCs. IPSCs were recorded by switching holding membrane potentials to voltages that corresponded to EPSC reversal potentials $(0 \mathrm{mV})$. In all experiments, membrane potentials were corrected for a liquid junction potential of $-10 \mathrm{mV}$. TC EPSCs and IPSCs were evoked by current pulses ( $100 \mu$ s duration) delivered to the thalamic radiation (TR) via tungsten bipolar electrodes (FHC, Inc.) placed in the white matter midway between the MGv and the ACx (rostral to the hippocampus). To ensure the specificity of LTP in thalamic inputs, independent intracortical inputs were concurrently tested with thalamic inputs by placing a second stimulating electrode in cortical layer I, $\sim 200 \mu \mathrm{m}$ lateral to the recording pipette. Independence of TR and corticocortical (CC) inputs was confirmed if no paired-pulse depression (a feature of TC synapses) or paired-pulse facilitation (a feature of CC synapses) was detected by alternated and reciprocal stimulation of TR and $\mathrm{CC}$ electrodes (50 ms interpulse interval). Stimulation intensities (TR, 50-300 $\mu \mathrm{A}$; CC, $130-170 \mu \mathrm{A}$ ) were adjusted during each experiment to elicit 150-200 pA EPSCs. In some experiments, inhibitory currents were blocked using picrotoxin (PTX). Because bath application of PTX causes epilepsy-like activity in TC slices and prevents the reliable recording of TC EPSCs and IPSCs, PTX (2-5 mM) was added to the intracellular solution (iPTX) as described previously (Inomata et al., 1988; Metherate and Ashe, 1993; Nelson et al., 1994; Yazaki-Sugiyama et al., 2009). This effectively blocked IPSCs in recorded neurons without inducing epilepsy-like activity in the slice.

EPSCs recorded in layer III/IV cortical neurons may contain monosynaptic (TC) and polysynaptic (corticothalamic and CC) components. We dissected a monosynaptic component using quantification of the initial slopes of EPSCs throughout the LTP experiments rather than EPSC peak amplitudes. Typically, EPSC slopes were measured within the first $2 \mathrm{~ms}$ of the EPSC trace based on the uniformity of the slope. This measurement window was chosen based on the observation that IPSC initiation, which is activated disynaptically, was delayed by $\sim 2 \mathrm{~ms}$ after EPSCs. Initial slopes of EPSCs evoked by TR stimulation had short onset latencies $(\leq 3 \mathrm{~ms})$ and low onset latency variability jitter $(<0.5 \mathrm{~ms})$, suggestive of activation of monosynaptic TC connections but not of detectable activation of polysynaptic connections during this $2 \mathrm{~ms}$ window (Blundon et al., 2011).

Electrical stimulation of the TR may activate corticothalamic projections antidromically that may contribute to the first $2 \mathrm{~ms}$ of the EPSC through activation of CC synapses (Beierlein and Connors, 2002). Because the contribution of these inputs is minimal in the $\mathrm{ACx}$ (Rose and Metherate, 2001), the first $2 \mathrm{~ms}$ of the EPSC is suggestive of activation of monosynaptic TC connections but not of activation of monosynaptic CC synapses during this $2 \mathrm{~ms}$ window. To ensure consistent access resistance of the recording electrode during the entire experiment, we monitored the peak amplitude of a brief $(10 \mathrm{~ms})$ hyperpolarizing test pulse $(-5 \mathrm{mV})$ given 250 $\mathrm{ms}$ after electrical, optogenetic stimulations, or glutamate uncaging. Access resistance in recorded neurons was typically $10-25 \mathrm{M} \Omega$. Recordings were discarded if access resistance was higher than $25 \mathrm{M} \Omega$ or if access resistance changed $>15 \%$ during the course of the whole-cell recording.

Two-photon imaging and glutamate uncaging. Two-photon laser-scanning microscopy was performed using an Ultima imaging system (Prairie Technologies), a titanium:sapphire Chameleon Ultra femtosecond-pulsed laser (Coherent), and $60 \times(0.9$ numerical aperture) water-immersion infrared objectives (Olympus) as described previously (Blundon et al., 2011). To visualize dendrites and dendritic spines, we included 10-25 $\mu \mathrm{M}$ Alexa Fluor 594 (820 nm excitation wavelength) in the intracellular solution. Dendritic spines were identified as protrusions emanating from a dendritic shaft. Based on previous data (Richardson et al., 2009), dendritic spines that were within $100 \mu \mathrm{m}$ of the soma on basal or oblique dendrites were chosen as putative sites of thalamic inputs.

For two-photon glutamate uncaging (TGU), 4-methoxy-7-nitroindolinyl (MNI)-glutamate (2.5 mM) was added to the recording ACSF. The timing 
and intensity of glutamate uncaging were controlled by TriggerSync (Prairie Technologies). In typical experiments, we delivered $0.2-0.5 \mathrm{~ms}$ pulses from a second titanium:sapphire Chameleon Ultra laser $(720 \mathrm{~nm})$ to a targeted dendritic spine and recorded uncaging-induced EPSCs (uEPSCs). The duration and intensity of illumination of the uncaging laser was then adjusted to induce responses that mimic miniature spontaneous EPSCs, which were recorded previously in layer III/IV neurons and averaged $\sim 10-15 \mathrm{pA}$ (Richardson et al., 2009). We then used these uncaging parameters (site, laser duration, and laser intensity) to conduct the TGU-induced LTP (TGULTP) experiments.

Optogenetic experiments. Adeno-associated viruses (AAVs) were generated from pAAV-CaMKII $\alpha$-hChR2(H134R)-mCherry-WPRE-pA $(\mathrm{CaMKII} \alpha-\mathrm{ChR} 2)$ and pAAV-EF1 $\alpha-\mathrm{DIO}-\mathrm{hChR} 2(\mathrm{H} 134 \mathrm{R})-\mathrm{eYFP}-$ WPRE-pA (EF1 $\alpha$-DIO-ChR2) plasmids (gift from Karl Deisseroth, Stanford University, Stanford CA) and produced commercially (serotype $2 / 1 ; 4 \times 10^{12} \mathrm{IFU} / \mathrm{ml}$; UNC Vector Core). Viruses were separated into $4 \mu \mathrm{l}$ aliquots and stored at $-80^{\circ} \mathrm{C}$. EF1 $\alpha$-DIO-ChR2 viruses were injected into the basal forebrain (NB) of ChAT-cre mice, and CaMKII $\alpha-$ ChR2 viruses were injected into the MGv of C57BL/6, $A_{1} R^{-/-}$, or ChATcre mice. For in vivo viral injections, young adult mice (3-4 weeks old) were anesthetized with isoflurane in pure oxygen $(2-3 \%$ induction and $1.0-1.5 \%$ maintenance) and head fixed in a stereotaxic device. Virus was injected with a metal cannula (28 gauge; Plastics One) using a standard procedure (Zakharenko et al., 2003; Cetin et al., 2006). Briefly, an incision was made in the scalp, and a small craniotomy was drilled. Individual aliquots of AAVs were thawed, and $2 \mu \mathrm{l}$ of virus was slowly pressure injected into the MGv or NB. We used the following coordinates measured from bregma: (1) MGv: anteroposterior, $-3.0 \mathrm{~mm}$; mediolateral, $\pm 1.8 \mathrm{~mm}$; dorsoventral, $3.2 \mathrm{~mm}$; (2) NB: anteroposterior, $-0.3 \mathrm{~mm}$; mediolateral, $\pm 1.8 \mathrm{~mm}$; dorsoventral, $-4.4 \mathrm{~mm}$. The cannula was left in place for 5-10 min before being slowly retracted. Approximately $21-28 \mathrm{~d}$ after virus injection, mice were decapitated, and TC slices were prepared. Two-photon imaging of mCherry in the MGv and enhanced yellow fluorescent protein (eYFP) in the NB was used to verify on-target infection of $\mathrm{CaMKII} \alpha-\mathrm{ChR} 2$ and EF1 $\alpha$-DIO-ChR2 viruses. Slices with off-target infection were not used. Short (1-2 ms, 10-200 mW), collimated light pulses from a $473 \mathrm{~nm}$ laser were directed to the slices through the visible light photoactivation module (Prairie Technologies) through the objective.

TC LTP experiments. TC LTP was induced by electrical stimulation of the TR, optogenetic stimulation of TC afferents, or TGU. LTP induced by electrical stimulation was induced by high-frequency trains ( 40 or 200 $\mathrm{Hz})$ of square electrical pulses $(100 \mu \mathrm{s})$. LTP induced by optogenetic stimulation was induced by $40 \mathrm{~Hz}$ trains of $473 \mathrm{~nm}$ laser pulses (1-2 ms). TGU-LTP was induced by identical $40 \mathrm{~Hz}$ trains of glutamate photolysis pulses $(0.2-0.5 \mathrm{~ms})$ to a single dendritic spine. Frequencies of 40 and 200 $\mathrm{Hz}$ were chosen based on in vivo data showing that thalamic neurons fire bursts of spikes in response to sound stimulation at $1-300 \mathrm{~Hz}$, with mean frequencies of $\sim 40 \mathrm{~Hz}$ (Massaux et al., 2004). The 40 and $200 \mathrm{~Hz}$ trains consisted of three periods delivered every $5 \mathrm{~min}$. Every period consisted of 10 trains of 40 or $200 \mathrm{~Hz}$ stimulations delivered for $200 \mathrm{~ms}$ every $5 \mathrm{~s}$. In all LTP experiments, baseline EPSCs were recorded using test stimulations in voltage-clamp mode (holding potential, $-70 \mathrm{mV}$ ) for up to 5 min before induction of LTP. For synaptic experiments (electrical or optogenetic stimulations), we delivered pairs of test stimulations $(0.05$ $\mathrm{Hz}$ ) with an interstimulus interval of $50 \mathrm{~ms}$. Paired-pulse depression of monosynaptic EPSCs ensured that we stimulated thalamic afferents. For TGU experiments, we delivered a train of single TGU pulses at $0.016 \mathrm{~Hz}$. All types of LTPs were induced in current-clamp mode while maintaining a steady resting potential of $-70 \mathrm{mV}$ using slow $(\tau=5 \mathrm{~s})$ current injection. After induction, the recordings were resumed in voltage-clamp mode at the same preinduction stimulation rate. In some experiments, we induced LTP using pairing of TR stimulation at $1 \mathrm{~Hz}$ (100 stimuli) with depolarization of postsynaptic cortical neurons to $0 \mathrm{mV}$ as described previously (Crair and Malenka, 1995). Pairing LTP was induced in voltage-clamp mode. Pharmacologic agonists or inhibitors were applied 15-20 min before induction of LTP and were washed out at the end of LTP induction.

LTP experiments were analyzed offline. For synaptically induced TC LTP, we compared EPSCs (initial $2 \mathrm{~ms}$ slope) recorded 50-60 min after
LTP induction with baseline EPSCs recorded before LTP induction. For TGU-LTP, we compared uEPSCs recorded 40-60 min after LTP induction with baseline uEPSCs. During TGU-LTP induction, precautions were taken to ensure that the TGU-induction protocol delivered pulses to a dendritic spine without damaging it or its parent dendrite. We monitored the dendritic spine position to ensure that the site of photolysis did not drift $>0.5 \mu \mathrm{m}$ during induction. The success of glutamate uncaging during LTP induction was also monitored by detecting uEPSCs. Experiments were discarded if TGU during LTP induction failed to produce detectable uEPSCs or if a targeted dendritic spine or its surrounding neuropil showed signs of distress attributable to local overheating.

CC LTD experiments were performed by delivering trains of 1 or 10 $\mathrm{Hz}$ stimulations through electrodes placed into layer III/IV 200-300 $\mu \mathrm{m}$ laterally from a recorded neuron. The $1 \mathrm{~Hz}$ protocol consisted of 900 pulses $(200 \mu \mathrm{s})$ delivered at $1 \mathrm{~Hz}$. The $10 \mathrm{~Hz}$ protocol consisted of three periods delivered every $5 \mathrm{~min}$. Each period consisted of 10 trains of $10 \mathrm{~Hz}$ stimuli $(200 \mu \mathrm{s})$ delivered for $1 \mathrm{~s}$ every $5 \mathrm{~s}$. Durations and intensities of synaptic stimulation and TGU pulses remained constant throughout an experiment.

Statistical analyses. Data are represented as means \pm SEM. All statistics were computed using SigmaPlot and SigmaStat software (Systat Software). LTP and LTD expression was determined by a paired $t$ test if the normality (Shapiro-Wilk) test passed or by the Wilcoxon's signed rank test if the normality test failed. Differences in mean data were considered significant if the $p$ value of the test result was $<0.05$.

\section{Results}

\section{Cortical disinhibition is required for TC LTP expression} beyond the early critical period

We used mice that had matured beyond the early critical period for LTP at TC synapses, which corresponds to the first few postnatal days in rodents (Crair and Malenka, 1995). To induce TC LTP in mature (P42-P56) mice, we performed whole-cell recordings from thalamorecipient layer III/IV pyramidal neurons in the $\mathrm{ACx}$ in acute brain slices containing the auditory thalamus (MGv) and ACx (Fig. 1a,b). We recorded EPSCs evoked by electrical stimulation of the white matter corresponding to the TR. Simultaneously, we imaged recorded neurons to ensure that they were pyramidal neurons, which are the main thalamorecipient cells in the granular layer of the ACx (Lund, 1973; Feldman and Peters, 1978; Smith and Populin, 2001; Richardson et al., 2009). As reported previously (Richardson et al., 2009; Blundon et al., 2011), a single electrical stimulation of the TR evoked a monosynaptic EPSC $\left(V_{\mathrm{h}}=-70 \mathrm{mV}\right)$ in layer III/IV cortical pyramidal neurons and a disynaptic (initiated $\sim 2 \mathrm{~ms}$ later) IPSC $\left(V_{\mathrm{h}}=0\right.$ $\mathrm{mV}$ ) (Fig. 1c). A pair of electrical stimulations (50 ms interpulse interval) produced paired-pulse depression of EPSCs, a characteristic feature of TC synaptic transmission (data not shown). To induce LTP at TC synapses, we established a short baseline of EPSCs (4-5 min to avoid cell dialysis) and then applied electrical tetanization to the TR. For this, we used 40 or $200 \mathrm{~Hz}$ trains of stimuli based on in vivo data showing that acoustic stimulation causes thalamic neurons to fire bursts of action potentials at 1-300 Hz, with mean frequencies of $\sim 40 \mathrm{~Hz}$ (Massaux et al., 2004). These tetanization patterns have been effective in induction of LTP at other central synapses (Grover and Teyler, 1990; Zakharenko et al., 2001). We also used a pairing protocol that was effective in induction of NMDAR-dependent TC LTP in slices from somatosensory cortex during the early critical period (Crair and Malenka, 1995). This protocol consisted of stimulation of the TR (100 stimuli at $1 \mathrm{~Hz}$ ) during direct postsynaptic depolarization of a layer III/IV pyramidal neuron (to between 10 and $0 \mathrm{mV}$ ). However, consistent with the notion of an early critical period for synaptic plasticity, neither the $40 \mathrm{~Hz}$ (Fig. 1d) nor the $200 \mathrm{~Hz}$ (Fig. le) tetanization protocol nor the pairing protocol (Fig. 1f) in- 
duced LTP of EPSCs at TC synapses in slices from mature mice. The EPSC slope measured 50-60 min (EPSC 60 ) after 40 or $200 \mathrm{~Hz}$ tetanization or after pairing was $98.9 \pm 14.8 \%(p=0.938, n=7$ neurons $)$, $82.1 \pm 11.1 \%(p=0.146, n=9$ neurons $)$, or $101.9 \pm 9.8 \%(p=0.704, n=5$ neurons) of baseline, respectively.

Previous reports have indicated that maturation of GABAergic inhibition may contribute to closing of the early critical period of plasticity in sensory cortices (Kirkwood and Bear, 1994a; Hensch et al., 1998). Moreover, it has been proposed that the GABAergic contribution is higher in slices than in in vivo preparations (Cooke and Bear, 2010) in which TC LTP can be induced in sensory cortices beyond the early critical period (Lee and Ebner, 1992; Heynen and Bear, 2001; Dringenberg et al., 2004, 2007; Hogsden and Dringenberg, 2009). To investigate the influence of cortical inhibition on LTP in the $\mathrm{ACx}$, we selectively blocked $\mathrm{GABA}_{\mathrm{A}^{-}}$ dependent inhibitory currents in recorded cortical neurons by applying picrotoxin intracellularly (iPTX). Consistent with previous reports (Inomata et al., 1988; Nelson et al., 1994; YazakiSugiyama et al., 2009; Blundon et al., 2011), this treatment completely eliminated evoked IPSCs without affecting EPSCs or causing epileptic activity in slices (Fig. $1 g$ ). In the presence of iPTX, both 40 and $200 \mathrm{~Hz}$ tetanus produced robust LTP at TC synapses of mature mice. The EPSC $_{60}$ after 40 and $200 \mathrm{~Hz}$ tetanization was $148.8 \pm 13.3 \%(p=0.005, n=11$ neurons $)$ and $157.3 \pm 15.1 \%(p=0.018$, $n=11$ neurons) of respective baselines (Fig. $1 h, i)$. These results are consistent with previous reports indicating that LTP can be induced at mature synapses during pharmacologic inhibition of $\mathrm{GABA}_{\mathrm{A}}$ transmission (Artola and Singer, 1987; Kirkwood and Bear, 1994a; Wang and Daw, 2003; but see Dudek and Friedlander, 1996; Jiang et al., 2007). These experiments also indicate that LTP of EPSCs is preserved at TC synapses of the ACx even after the closing of the early critical period but is masked, in part, by cortical inhibition. However, the pairing protocol failed to induce LTP in the presence of iPTX (Fig. 1j). The EPSC 60 after the pairing protocol was $89.2 \pm 9.8 \%$ ( $p=0.087, n=5$ neurons $)$ of baseline in the presence of iPTX. These results suggest that the properties of TC LTP in the ACx are different from that in the somatosensory cortex.

To ensure effectiveness of induction protocols, we tested TC LTP in slices from mice during the early critical period (P5-P7). No iPTX was added in these experiments. We found that TR tetanization $(40 \mathrm{~Hz})$ but not the pairing protocol was effective in induction of TC LTP in neonates (Fig. 2). The EPSC 60 after $40 \mathrm{~Hz}$ tetanus was $173.3 \pm 17.2 \%(p<0.001, n=7$ neurons $)$ of baseline but only $97.1 \pm 7.5 \%(p=0.978, n=10$ neurons $)$ of baseline after the pairing protocol. Thus, the pairing protocol that was effective to induce TC LTP in other sensory cortices was ineffective to induce TC LTP in the ACx in both neonates and mature b
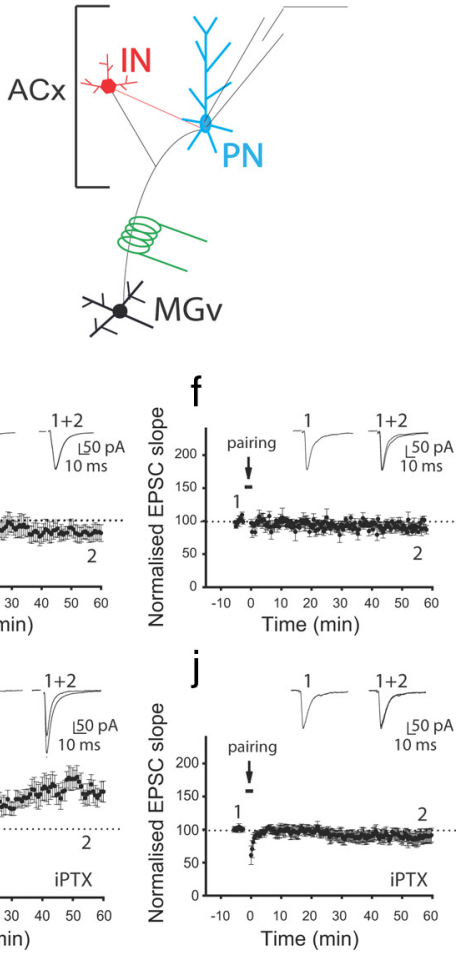

Figure 1. LTP at TC synapses requires cortical disinhibition to persist beyond the early critical period. $\boldsymbol{a}$, A diagram of the TC slice containing portions of the auditory thalamus (MGV), TR, and the ACx. Thalamorecipient layer III/IV (LIII/IV) neuron is shown in blue. A stimulating electrode (green) is placed into the white matter to activate the TR. Hipp., Hippocampus. $\boldsymbol{b}$, Top, A diagram of disynaptic IPSC in a layer III/IV pyramidal neuron in the ACX.d, e, Tetanization of the TR with $40 \mathrm{~Hz}$ (d) or $200 \mathrm{~Hz}$ (e) bursts fails to produce or $200 \mathrm{~Hz}$ (i) but not the pairing protocol (j) produces TC LTP in slices from mature animals in the presence of iPTX. Arrows indicate periods of TR tetanization. Insets show representative EPSCs recorded before (1) and 50-60 min after (2) induction of LTP.

animals. Therefore, we continued our experiments using highfrequency protocols that mimic bursting activity of thalamic neurons in response to sounds.

Because the pharmacologically induced block of $\mathrm{GABA}_{\mathrm{A}}$ transmission is not physiological, we attempted to achieve cortical disinhibition in slices from mature animals by using synaptic mechanisms. To this end, we induced LTD of IPSCs (iLTD) by

P5-P7
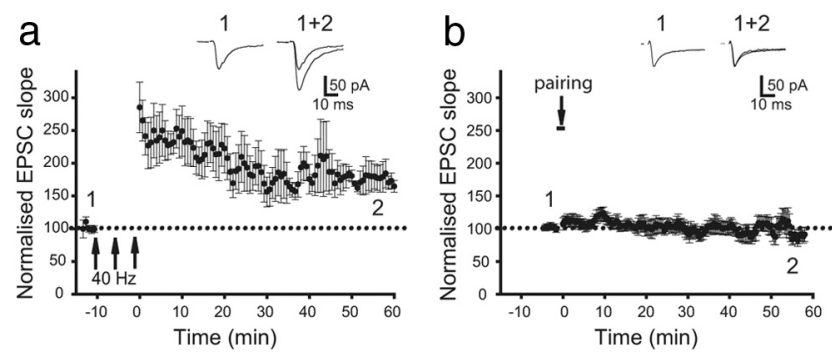

Figure 2. TC LTP in the ACx is readily induced in slices from neonates by high-frequency bursting activity but not by the pairing protocol. $\boldsymbol{a}, \boldsymbol{b}$, Normalized mean EPSC slope as a function of time before and after induction of TC LTP by $40 \mathrm{~Hz}$ tetanization of the TR ( $a$ ) or by the pairing protocol (b) in TC slices from neonatal (P5-P7) mice. Insets show representative EPSCs recorded before (1) and 50 - 60 min after (2) induction of LTP. 


\section{P42-P56}
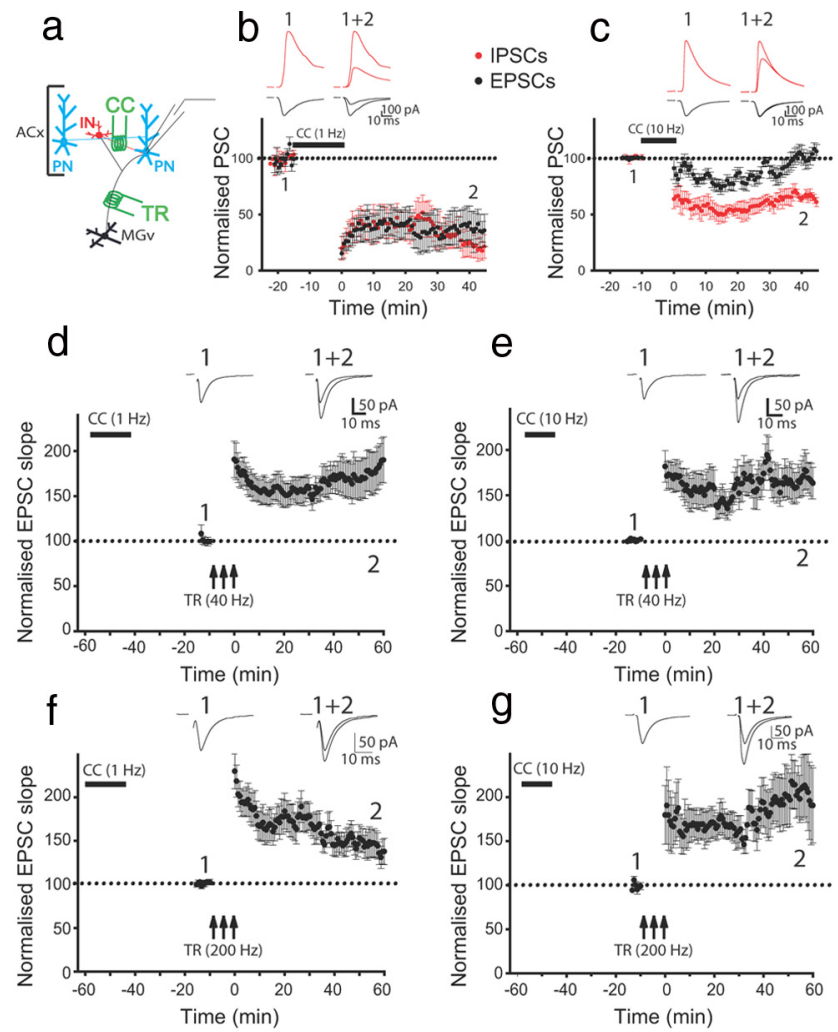

Figure 3. Synaptically induced cortical disinhibition unmasks TC LTP in slices from mature animals. $\boldsymbol{a}$, A diagram of $\mathrm{TC}$ and $\mathrm{CC}$ connections in the $\mathrm{ACx}$. Intracortical electrical stimulation activates $C($ excitatory and $C($ inhibitory inputs to thalamorecipient layer III/IV neurons in the $A C x$. Two stimulating electrodes (green) activate the TR and $C C$ inputs to the thalamorecipient neurons in the ACX. PN, Pyramidal neuron; IN, interneuron. $\boldsymbol{b}, \mathrm{A} 1 \mathrm{~Hz}$ train of $\mathrm{CC}$ stimulations produces LTD of CC IPSCs and CC EPSCs recorded in layer III/IV pyramidal neurons. C, A $10 \mathrm{~Hz}$ train of CC stimulations produces LTD of CC IPSCs but not CC EPSCs. $\boldsymbol{d}$-g, Tetanization at $40 \mathrm{~Hz}(\boldsymbol{d}, \boldsymbol{e})$ or $200 \mathrm{~Hz}(\boldsymbol{f}, \boldsymbol{g})$ of the TR that follows $1 \mathrm{~Hz}(\boldsymbol{d}, \boldsymbol{f})$ or $10 \mathrm{~Hz}(\boldsymbol{e}, \boldsymbol{g}) \mathrm{CC}$ trains is sufficient to produce TC LTP in slices from mature mice. Horizontal bars and arrows depict $C($ and TR stimulations, respectively. Insets show representative EPSCs recorded before (1) and after (2) induction of LTP.

stimulating CC projections (Fig. 3a). In these experiments no iPTX was used. The stimulating electrode was placed into layer III/IV of the ACx lateral to the recording electrode. We ensured that TR and CC electrodes stimulated two different subsets of projections in the ACx. Thus, no paired-pulsed depression (properties of TC synapses) or facilitation (properties of CC synapses) was detected when pairs of alternated stimulations (50 ms interpulse interval) were delivered through TR and CC electrodes (data not shown). Trains of electrical stimulation delivered through the CC electrode at 1 or $10 \mathrm{~Hz}$ produced a robust iLTD measured in layer III/IV neurons (Fig. 3b,c). CC IPSCs measured $30-40$ min after LTD induction were $36.3 \pm 13.2 \%(p<0.001$, $n=8$ neurons $)$ for $1 \mathrm{~Hz}$ and $67.6 \pm 4.8 \%(p<0.001, n=6$ neurons) for $10 \mathrm{~Hz}$ compared with respective baselines. Notably, only the $1 \mathrm{~Hz}$ train but not the $10 \mathrm{~Hz}$ train produced LTD of CC EPSCs in these experiments $(1 \mathrm{~Hz}, 39.8 \pm 17.3 \%$ of baseline, $p<$ $0.001, n=8$ neurons; $10 \mathrm{~Hz}, 106.4 \pm 13.7 \%$ of baseline, $p=$ $0.667, n=6$ neurons). Because both LTD protocols were effective in downregulating IPSCs, we investigated whether this synaptically induced cortical disinhibition would be sufficient for induction of TC LTP. To this end, we first delivered 1 or $10 \mathrm{~Hz}$ trains to CC projections, performed a whole-cell recording in nearby layer
III/IV neurons 30-40 min later, and then tetanized the TR using 40 or $200 \mathrm{~Hz}$ protocols. In all four conditions, we observed robust TC LTP. Thus, TC EPSC $_{60}$ was $173.3 \pm 18.1 \%$ of baseline $(p=$ $0.008, n=12$ neurons) for the CC $1 \mathrm{~Hz}$, TR $40 \mathrm{~Hz}$ protocol (Fig. $3 d), 165.6 \pm 17.9 \%$ of baseline ( $p=0.01, n=9$ neurons) for the CC $10 \mathrm{~Hz}$, TR $40 \mathrm{~Hz}$ protocol (Fig. 3e), $142.1 \pm 13.6 \%$ of baseline ( $p=0.013, n=11$ neurons) for the CC $1 \mathrm{~Hz}, \mathrm{TR} 200 \mathrm{~Hz}$ protocol (Fig. 3f), and $191.3 \pm 29.2 \%$ of baseline $(p=0.026, n=6$ neurons) for the CC $10 \mathrm{~Hz}$, TR $200 \mathrm{~Hz}$ protocol (Fig. $3 g$ ). Because both 1 and $10 \mathrm{~Hz}$ CC protocols caused iLTD but only the $1 \mathrm{~Hz}$ protocol caused LTD of CC EPSCs, it is likely that downregulation of CC IPSCs but not CC EPSCs is required for TC LTP. Together, these data argue that cortical disinhibition is required to unmask LTP at TC synapses in mature animals that are older than the early critical period.

\section{TC LTP is expressed postsynaptically and depends on group I mGluR-dependent mechanisms}

To elucidate the induction and expression mechanisms of TC LTP, we investigated whether this form of synaptic plasticity depends on calcium influx into postsynaptic neurons, as does LTP at many other central synapses (Blundon and Zakharenko, 2008). TC LTP induced in the presence of iPTX was blocked by calcium chelator BAPTA (10 mM) applied within the intracellular solution (iBAPTA), indicating that postsynaptic calcium is necessary for TC LTP induction (Fig. 4a). EPSC 60 was $99.1 \pm 15.5 \%$ of baseline ( $p=0.365, n=11$ neurons) in the presence of iBAPTA and iPTX. To further study postsynaptic mechanisms, we inves-
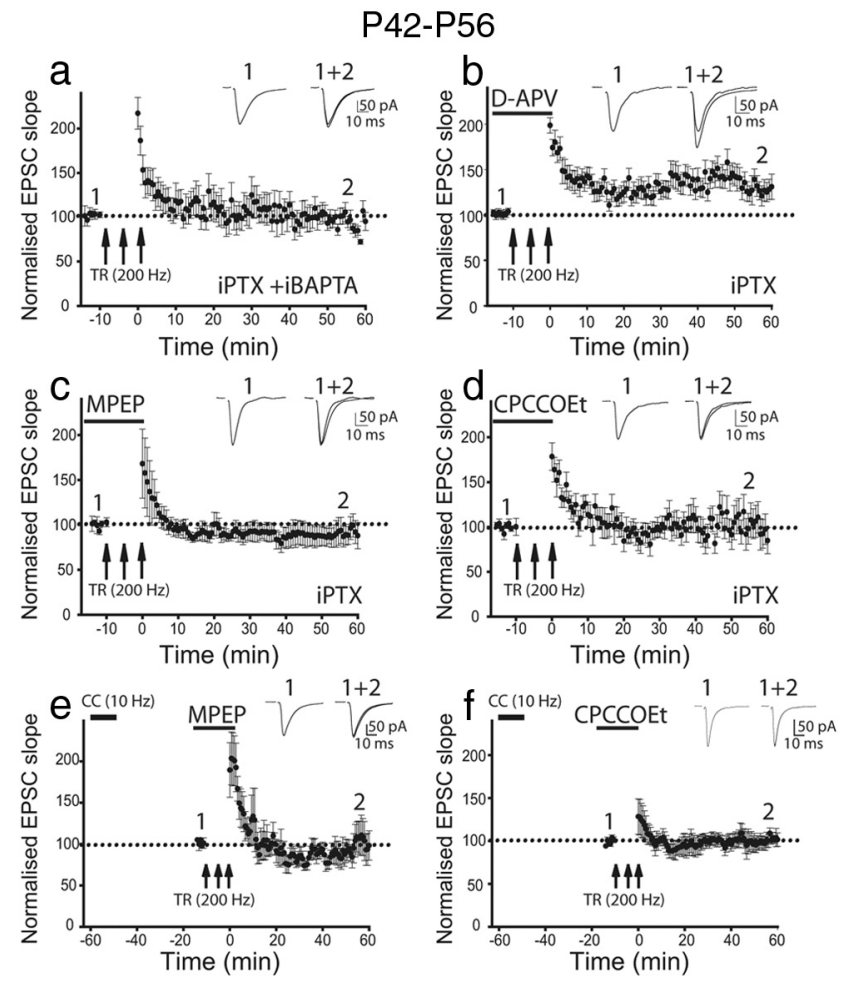

Figure 4. LTP at mature TC synapses in the ACx is expressed through group I mGluRs. $\boldsymbol{a}$, BAPTA in postsynaptic cells (iBAPTA) blocks TC LTP induced by $200 \mathrm{~Hz}$ TR tetanization in the presence of iPTX. $\boldsymbol{b}$, NMDAR blocker D-APV is ineffective at blocking TC LTP. $\boldsymbol{c}-\boldsymbol{f}$, Group I mGluR inhibitors MPEP $(\boldsymbol{c}, \boldsymbol{e})$ and CPCCOEt $(\boldsymbol{d}, \boldsymbol{f})$ block TC LTP induced by $200 \mathrm{~Hz}$ tetanization of the TR in the presence of iPTX $(\boldsymbol{c}, \boldsymbol{d})$ or after cortical disinhibition induced by $\mathrm{CC} 10 \mathrm{~Hz}$ stimulation $(\boldsymbol{e}, \boldsymbol{f})$. Arrows depict $200 \mathrm{~Hz}$ tetanization of the TR. Horizontal bars indicate bath application of antagonists. Insets show representative EPSCs recorded before (1) and after (2) $200 \mathrm{~Hz}$ stimulation of the TR. 


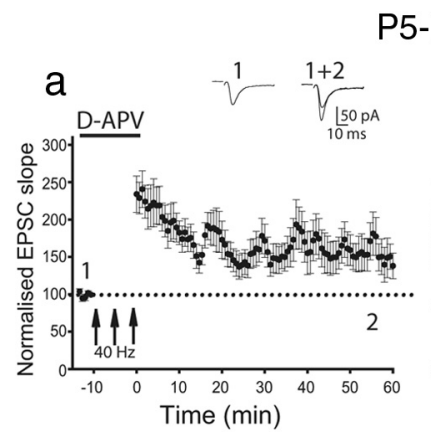

\section{P5-P7}

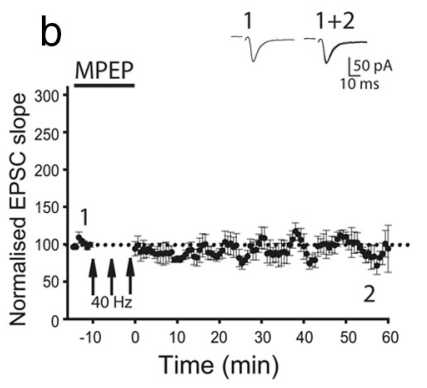

Figure 5. LTP at TC synapses in the neonatal $A C x$ is expressed through group I mGluRs but not NMDARs. $\boldsymbol{a}$, NMDARs blocker D-APV does not prevent TC LTP in slices from neonate mice. $\boldsymbol{b}$, Group I mGluR inhibitor MPEP blocks TC LTP in neonates. Arrows depict $40 \mathrm{~Hz}$ tetanization of the TR. Horizontal bars indicate bath application of antagonists. Insets show representative EPSCS recorded before (1) and after (2) $40 \mathrm{~Hz}$ tetanization of the TR.

tigated whether NMDARs or mGluRs are required for TC LTP. We found that group I mGluRs but not NMDARs are needed for induction of this form of synaptic plasticity (Fig. $4 b-d$ ). Specifically, group I mGluR $\left(\mathrm{mGluR}_{5}\right)$ antagonist MPEP $(10 \mu \mathrm{M})$ or group I $\left(\mathrm{mGluR}_{1}\right)$ antagonist CPCCOEt $(40 \mu \mathrm{M})$ but not NMDAR antagonist D-APV $(50 \mu \mathrm{M})$ blocked TC LTP induced in the presence of iPTX. EPSC 60 was $127.5 \pm 13.4 \%$ of baseline $(p=$ $0.02, n=14$ neurons), $92.3 \pm 12.1 \%$ of baseline $(p=0.549, n=$ 8 neurons), and $97.7 \pm 16.2 \%$ of baseline ( $p=0.341, n=13$ neurons) in the presence of D-APV, MPEP, or CPCCOEt, respectively.

The similar results were received for TC LTP induced in the presence of cortical disinhibition achieved synaptically. MPEP or CPCCOEt were effective in blocking TC LTP induced by TR tetanization after $10 \mathrm{~Hz}$ CC stimulation (Fig. $4 e, f$ ). EPSC 60 was $98.3 \pm 4.1 \%(p=0.651, n=6$ neurons $)$ and $97.7 \pm 8.0 \%(p=$ $0.788, n=6$ neurons) of baseline in the presence of MPEP and CPCCOEt, respectively. Although MPEP was effective in blocking TC LTP, neither MPEP nor D-APV affected depolarization of a postsynaptic neuron caused by electrical tetanization of the TR during induction of LTP ( $p>0.05$; data not shown), suggesting that these drugs do not affect glutamate release from TC projections. These data indicate that TC LTP in the ACX induced in mature mice in the presence of cortical disinhibition, induced either pharmacologically or synaptically, is dependent on group I mGluRs but not NMDARs as in other sensory cortices. This raised the question whether ACx TC LTP is devoid of NMDARdependent mechanisms or whether there is a developmental switch between NMDAR- and mGluR-dependent mechanisms of TC LTP during the closure of the early critical period. To address these possibilities, we tested TC LTP in neonates (P5P7). TR tetanization with $40 \mathrm{~Hz}$ (no iPTX was present in these experiments) produced a robust TC LTP in the presence of the NMDAR inhibitor but not the mGluR inhibitor (Fig. 5). Thus, EPSC $_{60}$ was $151.9 \pm 22.9 \%(p=0.003, n=13$ neurons $)$ and $93.5 \pm 17.7 \%(p=0.091, n=8$ neurons $)$ of baseline in the presence of D-APV and MPEP, respectively. As in mature mice, neither inhibitor affected short-term depolarization of a postsynaptic neuron evoked by electrical tetanization of the TR during induction of LTP ( $p>0.05$; data not shown). Together, these results indicate that TC LTP in the ACx uses group I mGluRdependent mechanisms in contrast to NMDAR-dependent mechanisms in other sensory cortices.

These data also suggest that LTP can be expressed at TC projections via postsynaptic mechanisms. To test directly whether
TC LTP is expressed postsynaptically, we used TGU to activate individual dendritic spines that are the postsynaptic sites of thalamic inputs. Because TGU releases exogenous glutamate from inactive (caged) glutamate (MNI-glutamate) and thereby bypasses the release of endogenous neurotransmitter from thalamic terminals, this method tests only postsynaptic mechanisms of synaptic transmission and plasticity (Matsuzaki et al., 2001). Previously, we mapped active postsynaptic sites of thalamic inputs on dendritic trees of thalamorecipient layer III/IV pyramidal neurons in the mouse ACx (Richardson et al., 2009) and found that thalamic inputs preferentially form synapses onto dendritic spines within $100 \mu \mathrm{m}$ of the soma. We targeted these proximal spines individually with TGU and evoked glutamate uEPSCs that mimicked miniature EPSCs (10-15 pA). In these experiments, we did not apply iPTX because MNI-glutamate, besides being a source of exogenous glutamate, is also a potent $\mathrm{GABA}_{\mathrm{A}}$ blocker (Kantevari et al., 2010). Indeed, bath application of MNIglutamate in concentrations used for TGU (2-5 mM) blocked electrically induced IPSCs at TC synapses (data not shown). To prevent epileptic activity in the presence of MNI-glutamate and eliminate the contribution of any neuronal network activity in TGU experiments, we applied the voltage-gated sodium channel blocker TTX $(2 \mu \mathrm{M})$ to the extracellular solution. Together, these treatments ensure that TGU activates only a targeted dendritic spine. After establishing a stable baseline of uEPSCs at a targeted dendritic spine, we applied a TGU induction protocol that replicated an induction protocol used for electrically induced TC LTP. Because application of the $200 \mathrm{~Hz}$ TGU protocol was technically challenging in these experiments as a result of frequent damage of the neuropil by TGU applied more frequently than $50 \mathrm{~Hz}$ (data not shown), we induced LTP using the $40 \mathrm{~Hz}$ protocol. We found that the $40 \mathrm{~Hz}$ TGU reliably induced LTP at proximal dendritic spines of layer III/IV cortical neurons in mature mice (Fig. 6a), suggesting that TC LTP is expressed postsynaptically. Thus, uEPSC measured after application of the $40 \mathrm{~Hz}$ TGU was $183.7 \pm$ $28.0 \%$ of baseline ( $p=0.017, n=8$ neurons). TGU-induced LTP developed slower than electrically induced LTP. Specifically, TGU-induced LTP lacked transient posttetanic potentiation that lasted $\sim 5$ min after tetanus, perhaps indicating that, during this short period, electrically induced TC LTP is partially expressed presynaptically. Nevertheless, mechanisms of TGU-induced TC LTP were similar to that of electrically induced TC LTP. Similar to electrically induced TC LTP, TGU-induced TC LTP was

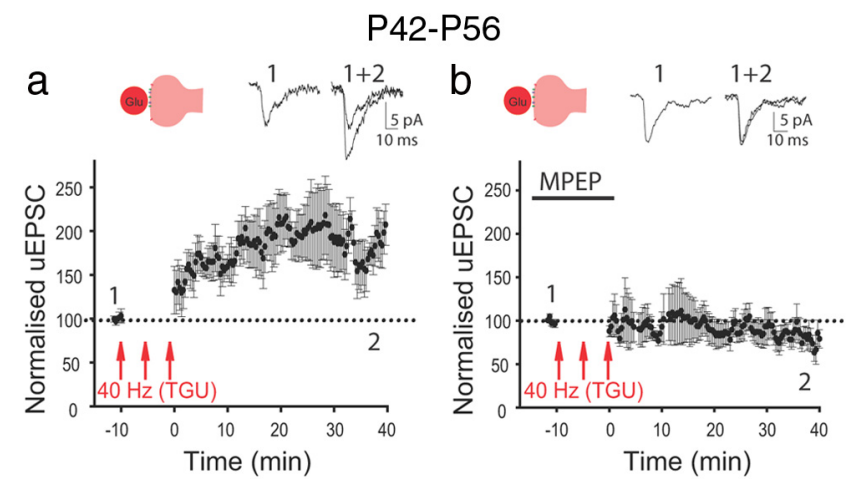

Figure 6. Postsynaptic mechanisms of TC LTP are mediated by group I mGluRs. $\boldsymbol{a}, \boldsymbol{b}$, Mean uEPSCs as a function of time before and after delivery of the $40 \mathrm{~Hz}$ TGU induction protocol to individual dendritic spines that are sites of thalamic inputs on layer III/IV neurons in the mature ACX in the absence (a) or presence (b) of MPEP. Arrows depict the $40 \mathrm{~Hz}$ TGU protocol. Insets show representative uEPSCs recorded before (1) and after (2) the $40 \mathrm{~Hz}$ TGU protocol applied to a dendritic spine. 


\section{P42-P56}
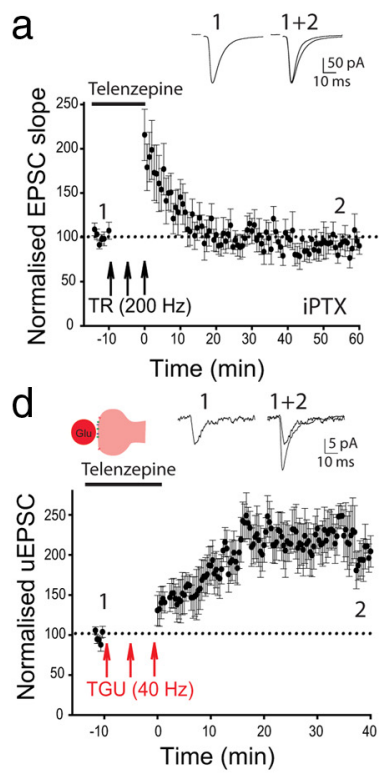

g

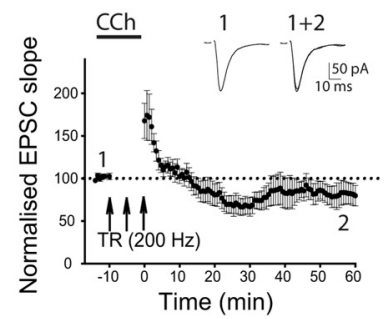

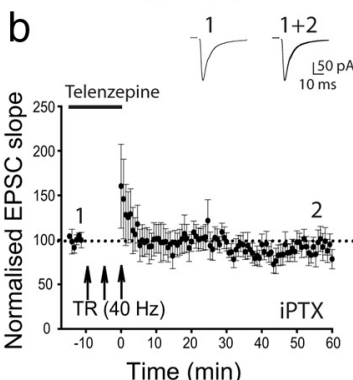

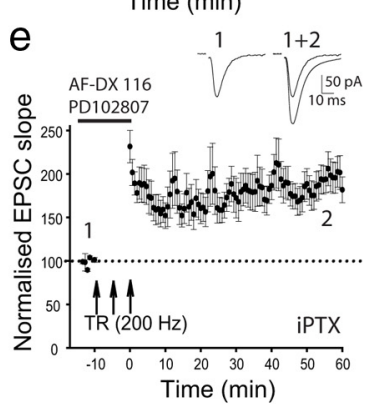

Time (min)
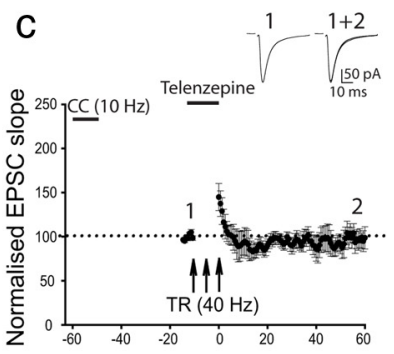

Time (min)

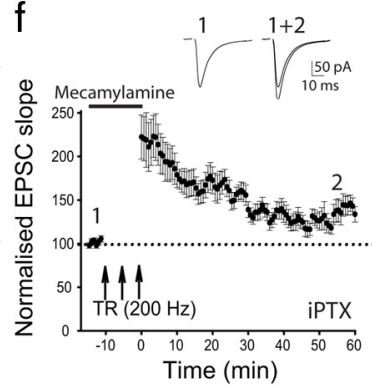

Time (min)

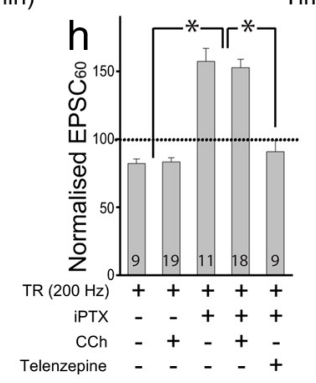

Figure 7. Presynaptic $M_{1} R$ s are required for LTP at mature TC synapses. $\boldsymbol{a}-\boldsymbol{d}, M_{1} R$ inhibitor telenzepine blocks TC LTP induced by $200 \mathrm{~Hz}(\boldsymbol{a})$ or $40 \mathrm{~Hz}(\boldsymbol{b}, \boldsymbol{c})$ electrical tetanization of the TR in the presence of PTX $(\boldsymbol{a}, \boldsymbol{b})$ or after synaptically induced cortical disinhibition (c) but not by TGU (d) .e, $\boldsymbol{f}$, Mean EPSC slopes as a function of time before and after $200 \mathrm{~Hz}$ tetanization of the TR in the presence of $\mathrm{PPTX}$ and $\mathrm{M}_{2}$ R and $\mathrm{M}_{2}$ R inhibitors AF-DX 116 and PD 102807 (e) or an inhibitor of nicotinic receptor mecamylamine $(\boldsymbol{f})$. $\boldsymbol{g}$, Pairing $200 \mathrm{~Hz}$ tetanization of the TR with bath application of cholinergic agonist CCh is not sufficient to induce TC LTP. Arrows depicts 200 or $40 \mathrm{~Hz}$ tetanization of the TR. Insets show representative EPSCS or uEPSCs recorded before (1) and after (2) tetanization of the TR or TGU stimulation of a dendritic spine. Horizontal bars indicate bath application of antagonists or $10 \mathrm{~Hz} \mathrm{CC}$ stimulation (c). $\boldsymbol{h}$, Cholinergic activation of $\mathrm{M}_{1}$ Rs is necessary but not sufficient for TC LTP induced by electrical tetanization of the TR. Numbers of slices are shown inside the bars. ${ }^{*} p<0.05$.

blocked by a group I mGluR antagonist (Fig. 6b). Thus, uEPSCs measured after the $40 \mathrm{~Hz}$ TGU protocol were $89.0 \pm 13.1 \%$ of baseline ( $p=0.146, n=8$ neurons) in the presence of MPEP. Together, these experiments indicate that LTP can be induced postsynaptically through activation of group I mGluRs and is expressed postsynaptically at TC synapses beyond the early critical period.

\section{$M_{1}$ cholinergic receptors are necessary for LTP at mature TC synapses}

These and our previous data (Blundon et al., 2011) show that TC synapses can undergo bidirectional long-term synaptic plasticity in the forms of LTP and LTD even after the end of the early critical period. LTD can be expressed at mature TC synapses during suppression of presynaptic gating that controls neurotransmitter release during low-frequency trains of TR stimulations (Blundon et al., 2011). Specifically, activation of presynaptic $M_{1} R s$ negatively regulates presynaptic adenosine signaling and thereby maintains sustained neurotransmitter release from thalamic projections during induction of TC LTD. In the absence of $M_{1} R$ activation, glutamate release from thalamic projections undergoes activity- dependent depression that prevents sufficient activation of postsynaptic group I mGluRs and, as a consequence, LTD fails to occur. LTD at mature TC synapses can be induced by pairing a $1 \mathrm{~Hz}$ train of TR stimulations with a bath application of the cholinergic agonist carbachol (CCh) and is blocked by the $M_{1} R$ antagonist telenzepine (Blundon et al., 2011). We reasoned that glutamate release from thalamic projections should be controlled in a similar manner during LTP induction, and therefore TC LTP could be gated by similar mechanisms.

First, we investigated whether $M_{1}$ Rs are necessary for LTP at mature TC synapses. We attempted to induce TC LTP in the presence of iPTX and the $M_{1} R$ inhibitor telenzepine $(0.1 \mu \mathrm{M})$. TC LTP induced by either $200 \mathrm{~Hz}$ (Fig. 7a) or $40 \mathrm{~Hz}$ (Fig. $7 b$ ) in the presence of iPTX was blocked by telenzepine, suggesting that, like TC LTD, TC LTP also depends on $M_{1}$ Rs. EPSC $_{60}$ was $90.1 \pm 9.8 \%$ of baseline $(p=$ $0.292, n=9$ neurons) for $200 \mathrm{~Hz}$ TR tetanus and $86.1 \pm 8.9 \%$ of baseline $(p=$ $0.169, n=7$ neurons) for $40 \mathrm{~Hz}$ TR tetanus in the presence of telenzepine. Similarly, TC LTP induced by $40 \mathrm{~Hz}$ in the presence of synaptically induced disinhibition was blocked by telenzepine (Fig. $7 c)$. EPSC $_{60}$ was $96.6 \pm 10.8 \%$ of baseline ( $p=0.775, n=6$ neurons) for $40 \mathrm{~Hz} \mathrm{TR}$ tetanus applied after $10 \mathrm{~Hz}$ CC stimulation in the presence of telenzepine.

Consistent with the notion of a presynaptic locus of LTP gating by $\mathrm{M}_{1} \mathrm{Rs}$, TGU induced robust LTP at thalamic inputs of layer III/IV cortical neurons even when $\mathrm{M}_{1}$ Rs were inhibited (Fig. $7 d$ ). Specifically, telenzepine failed to block postsynaptically expressed TC LTP [uEPSCs increased to $191.5 \pm 20.8 \%$ of baseline ( $p=0.003, n=8$ neurons)]. Inhibitors of $\mathrm{M}_{2}$ and $\mathrm{M}_{4}$ muscarinic receptors $\left(\mathrm{M}_{2} \mathrm{Rs}\right.$ and $\mathrm{M}_{4} \mathrm{Rs}$, respectively) (Fig. $7 e$ ) or nicotinic receptors (Fig. $7 f$ ) were not effective in blocking TC LTP. Nicotinic receptors modulate excitability of thalamic projections to the ACx (Kawai et al., 2007), but these and previous data (Blundon et al., 2011 ) indicate that these receptors are not involved in mechanisms of TC LTP or TC LTD. EPSC 60 was $187.3 \pm 33.1 \%$ of baseline $(p=$ $0.03, n=9$ neurons) in the presence of the $\mathrm{M}_{2} \mathrm{R}$ antagonist AF-DX 116 [11-([2-[(diethylamino)methyl]-1-piperdinyl] acetyl)-5, 11dihydro-6H-pyrido[2,3-b][1,4]benzodiaze pine-6-one] $(0.1 \mu \mathrm{M})$ and $\mathrm{M}_{4} \mathrm{R}$ antagonist PD $102807[(S)-(+)-(4 \mathrm{a} R, 10 \mathrm{~b} R)-3,4,4 \mathrm{a}, 10 \mathrm{~b}-$ tetrahydro-4-propyl-2 $H, 5 H$-[1]benzopyrano-[4,3-b]-1,4-oxazin9-ol] $(0.2 \mu \mathrm{M})$ or $145.2 \pm 10.7 \%$ of baseline $(p=0.002, n=11$ neurons) in the presence of nicotinic receptor antagonist mecamylamine $(1 \mu \mathrm{M})$. These data indicate that TC LTP, like TC LTD, is gated by presynaptic $\mathrm{M}_{1}$ Rs.

If $M_{1}$ Rs are necessary for TC LTP, would activation of these receptors be sufficient to suppress presynaptic gating? Application of CCh to the external solution failed to induce TC LTP by electric tetanization alone. Thus, pairing $200 \mathrm{~Hz}$ electrical stimulation of the TR with bath application of CCh $(5 \mu \mathrm{M})$ without 
iPTX was not sufficient to induce LTP at TC synapses (Fig. 7g). Furthermore, CCh was not effective at augmenting the TC LTP induced by $200 \mathrm{~Hz}$ TR tetanization in the presence of iPTX (Fig. $7 h$ ). Together, our experiments indicate that both cortical disinhibition and presynaptic $M_{1}$ Rs are necessary for TC LTP. However, cholinergic activation is not sufficient to change properties of electrically induced TC LTP.

\section{Cholinergic projections from the NB enter the ACx through the TR}

Because $M_{1} R$ antagonist telenzepine was effective at blocking electrically induced TC LTP, and the cholinergic agonist CCh failed to change the properties of electrically induced TC LTP, we hypothesized that electrical stimulation of the TR may indiscriminately activate not only TC projections but also other inputs to the $\mathrm{ACx}$, including cholinergic projections. To determine whether the TR contains cholinergic projections, we expressed the fluorescent proteins mCherry and eYFP in thalamic excitatory neurons and cholinergic neurons of the basal forebrain (NB), respectively, using recombinant AAVs (rAAVs) (Fig. 8a). The NB is the main source of cholinergic projections to the ACx, and its activation is thought to be involved in experiencedependent plasticity processes in the ACx (Bakin and Weinberger, 1996; Kilgard and Merzenich, 1998; Ma and Suga, 2003). To express eYFP specifically in cholinergic neurons, we injected rAAVs encoding eF1 $\alpha$ ::DIO-eYFP (double-floxed inverse open reading frame of eYFP under the control of the ubiquitous eF1 $\alpha$ promoter) into the $\mathrm{NB}$ of mice that express cre recombinase exclusively in cholinergic neurons (ChAT-cre mice). To express mCherry in the same mice, we injected rAAVs that encode CaMKII $\alpha::$ mCherry (mCherry under the control of the excitatory neuron-specific promoter CaMKII $\alpha$ ) into the MGv. Twophoton imaging of the TR in TC slices from mature mice revealed bright mCherry- and eYFP-labeled projections in the locus in which the stimulating electrode is usually placed during TC LTP experiments (Fig. 8a). These data indicate that the TR indeed contains not only TC projections from the MGv but also cholinergic projections from the NB. We also identified that cholinergic projections are present in the $\mathrm{ACx}$ in the close vicinity of thalamorecipient layer III/IV neurons (Fig. 8b). In these experiments, we injected rAAVs encoding eF1 $\alpha:$ DIO-eYFP into the $\mathrm{NB}$ of ChAT-cre mice and filled a layer III/IV pyramidal neuron with cytoplasmic dye Alexa Fluor 594 through a patch pipette. Two-photon imaging revealed that the ACx, including the layer III/IV, contains a net of cholinergic projections. Because TC projections and cholinergic projections from the NB overlap within the TR, intense electrical stimulation of the white matter that we use during induction of TC LTP may activate both projections and thus release both glutamate and acetylcholine onto cortical neurons in the ACx.

\section{Optogenetic activation of TC projections reveals that TC LTP is gated by cholinergic inputs from the NB}

The previous experiment showed that electrical tetanization of the TR may activate not only TC projections but also cholinergic projections from the NB. Furthermore, previous works indicate that such stimulation may also antidromically activate corticothalamic projections (Beierlein and Connors, 2002). To exclusively activate TC projections, we used an optogenetic approach. To this end, we expressed channelrhodopsin-2(H134R) (ChR2) in excitatory MGv neurons of mature mice using rAAVs that encode CaMKII $\alpha$ ::ChR2-mCherry (Fig. 9a). A brief optical pulse $(473 \mathrm{~nm})$ delivered to a layer III/IV pyramidal neuron evoked a monosynaptic EPSC (oEPSC) and a disynaptic IPSC (oIPSC) in layer III/IV neurons (Fig. 9b), and a pair of such optical pulses (50 $\mathrm{ms}$ interpulse interval) produced paired-pulse depression of oEPSCs (Fig. 9c) suggesting that we activated TC synapses. To induce TC LTP, we replaced high-frequency electrical tetanus with the same pattern of optical stimulations. In these experiments, we chose to use the $40 \mathrm{~Hz}$ tetanus because many neurons cannot follow ChR2-driven spiking above $40 \mathrm{~Hz}$ in sustained trains (Boyden et al., 2005; Gunaydin et al., 2010). We recorded oEPSCs before and after optical tetanization of TC projections. This tetanization failed to produce TC LTP in slices of mature mice even in the presence iPTX (Fig. $9 d$ ). Specifically, oEPSC 60 was $93.5 \pm 8.1 \%$ of baseline ( $p=0.282, n=6$ neurons), suggest-

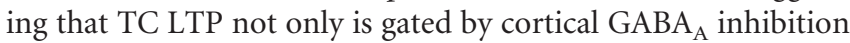
but also requires release of an additional gating mechanism. Because TC LTP is $M_{1} R$ dependent, we reasoned that TC LTP can be gated by both cortical GABA ${ }_{A}$ inhibition and $\mathrm{M}_{1}$ Rs. Consistent with this view, optical tetanization of TC projections paired with bath-applied CCh and iPTX was sufficient to produce robust TC LTP (Fig. 9e). Thus, oEPSC $_{60}$ in these experiments was $221.4 \pm$ $31.6 \%$ of baseline ( $p=0.013, n=8$ neurons). In contrast, CCh application alone did not affect $\mathrm{EPSC}_{60}$ (Blundon et al., 2011) or oEPSC $_{60}$ (data not shown).

To confirm our hypothesis, we attempted to optogenetically stimulate both TC and cholinergic projections in the presence of iPTX. ChR2 was expressed in MGv excitatory neurons and NB cholinergic neurons by injecting rAAVs encoding CaMKII $\alpha::$ ChR2-mCherry into the MGv and rAAVs encoding eF1 $\alpha:$ :DIO-ChR2-eYFP into the NB of ChAT-cre mice (Fig. 9f). Optical tetanization $(40 \mathrm{~Hz})$ of both thalamic and cholinergic projections expressing ChR2 in the presence of iPTX was sufficient to induce robust TC LTP. Thus, oEPSC 60 was $207.2 \pm$ $24.3 \%$ of baseline ( $p=0.005, n=6$ neurons). In contrast, optical tetanization of TC and cholinergic projections in the absence of iPTX failed to induce TC LTP (Fig. $9 g$ ). Thus, oEPSC $_{60}$ was $109.8 \pm 13.6 \%$ of baseline ( $p=0.674, n=5$ neurons $)$, consistent with the idea that two independent mechanisms, activation of presynaptic $\mathrm{M}_{1}$ Rs and cortical disinhibition, are both required to unmask LTP at TC synapses in slices of mature animals.

Optical tetanization of both thalamic and cholinergic projections in the presence of iPTX failed to induce LTP when telenzepine was present in the bath solution, confirming the requirement of $\mathrm{M}_{1} \mathrm{Rs}$ for this form of LTP (Fig. 9h). Thus, oEPSC $_{60}$ was $93.7 \pm 8.72 \%$ of baseline ( $p=0.341, n=6$ neurons) in the presence of telenzepine. Similarly, MPEP blocked this form of LTP (Fig. 9i). In the presence of MPEP, EPSC $_{60}$ was $76.2 \pm 16.7 \%$ of baseline $(p=0.321, n=9$ neurons), confirming that group I mGluRs are required for TC LTP in mature animals.

\section{Genetic ablation of $A_{1} R s$ bypasses a requirement of $M_{1} R$ activation for TC LTP}

In our previous work, we showed that downregulation of adenosine signaling by $\mathrm{M}_{1} \mathrm{R}$ activation maintains sustained glutamate release from thalamic terminals in the $\mathrm{ACx}$ (Blundon et al., 2011). $A_{1} R$ deletion or pharmacological inhibition was sufficient to induce TC LTD even when $M_{1}$ Rs were blocked with telenzepine. Thus, $A_{1} R$ deletion or inhibition bypasses the requirement for $M_{1} R$ activation for induction of TC LTD. We hypothesized that a similar mechanism might be at work during TC LTP. To this end, we used slices from mature mutant mice lacking $\mathrm{A}_{1} \mathrm{Rs}$ $\left(A_{1} R^{-1-}\right.$ mice $)$. These mice have a normal lifespan and have no gross abnormalities (Johansson et al., 2001). We found that TC LTP can be induced in these mice even in the presence of the $M_{1} R$ 


\section{P42-P56}

a ChAT-cre mice
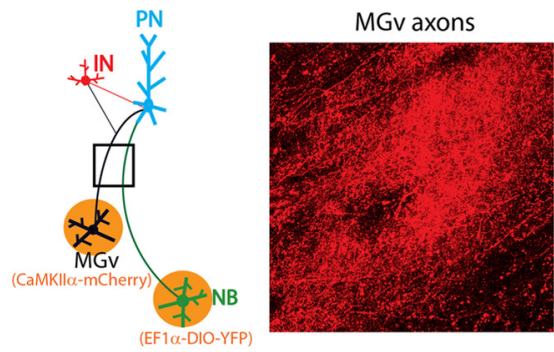

b

ChAT-cre mice

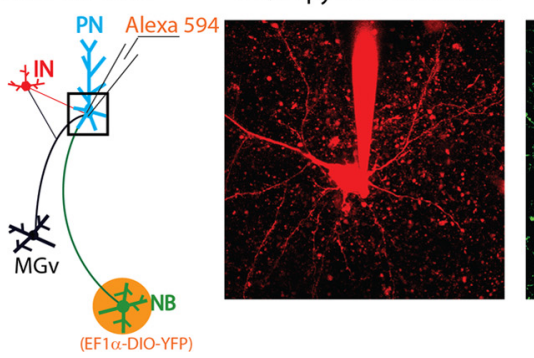

LIII/IV pyramidal neuron

Thalamic radiation NB axons

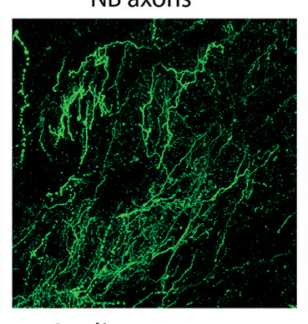

Auditory cortex

NB axons
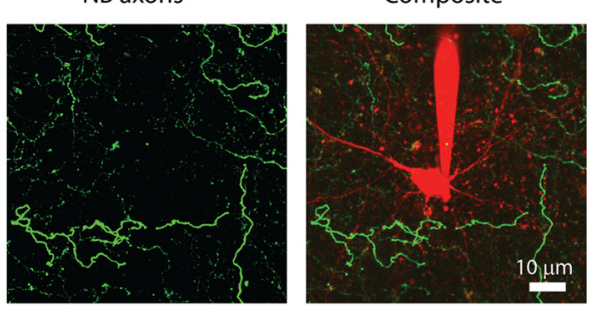

Figure 8. Cholinergic projections from the NB are contained in the TR and the ACX. $\boldsymbol{a}$, Left, AAVs encoding CaMKIl $\alpha$-mCherry and EF1 $\alpha$-DI0-eYFP were injected (orange) into the MGv and the NB, respectively, of the ChAT- cre mice. Right, Visualization of mCherry-labeled glutamatergic (red) and eYFP-labeled cholinergic (green) projections in the TR. IN, Interneuron. $\boldsymbol{b}$, Left, AAVs encoding EF1 $\alpha$-DI0 - eYFP were injected (orange) into the NB of the ChAT- cre mice. Right, Visualization of layer III/IV (LIII/IV) pyramidal neuron (red) filled with Alexa Fluor 594 through a patch pipette and cholinergic projections from the NB (green) in the $A C x$.

inhibitor telenzepine. In all these experiments, iPTX was present. EPSC $_{60}$ was enhanced after $40 \mathrm{~Hz}$ (Fig. 10a) or $200 \mathrm{~Hz}$ (Fig. 10b) electrical tetanization of the TR in the presence of telenzepine to $160.3 \pm 11.1 \%$ ( $p=0.002, n=11$ neurons $)$ or $162.7 \pm 8.9 \%$ ( $p<0.001, n=6$ neurons) of baseline. Similarly, pharmacological inhibition of $A_{1} R s$ in wild-type mice with 8-cyclopentyl-1,3dipropylxanthine (DPCPX) $(1 \mu \mathrm{M})$ was sufficient for $40 \mathrm{~Hz}$ electrical tetanization of the TR to produce TC LTP in the presence of telenzepine (Fig. 10c). On average, EPSC $_{60}$ was $162.5 \pm$ $15.6 \%$ of baseline ( $p=0.0002, n=12$ neurons) in the presence of DPCPX and IPTX in slices of wild-type mice. These data are consistent with the notion that $\mathrm{M}_{1} \mathrm{R}$ activation negatively regulates adenosine machinery in thalamic terminals and thus releases LTP and LTD gating at TC synapses. Also, consistent with this notion, optogenetic tetanization of TC inputs in $A_{1} R^{-/-}$ mice was sufficient to produce robust TC LTP (Fig. 10d), whereas the same experiments in wild-type mice failed to induce TC LTP (Fig. 9d). Thus, oEPSC 60 was $255.7 \pm 30.1 \%$ of baseline $(p<$ $0.001, n=10$ neurons) after $40 \mathrm{~Hz}$ optogenetic tetanization in the presence of iPTX in slices of $A_{1} R^{-\prime-}$ mice. TC LTP induced by this methods in $A_{1} R^{-/-}$mice was significantly different from TC LTP in wild-type mice $(p<0.001)$, which failed to be induced without additional activation of cholinergic receptors. These data strongly suggest that adenosine signaling through $\mathrm{A}_{1}$ Rs underlies gating of TC LTP in a manner similar to that of TC LTD: by dampening sustained glutamate release and thereby preventing sufficient activation of postsynaptic group I mGluRs. Once the adenosine machinery is suppressed, glutamate release from thalamic terminals is enhanced during repetitive stimulations and becomes sufficient to trigger mGluR-dependent TC LTP or LTD, and activation of presynaptic $\mathrm{M}_{1} \mathrm{Rs}$ is no longer required (Blundon et al., 2011).

\section{Discussion}

Here we show TC synapses in the ACx retain their capabilities for LTP even after the end of the early critical period for synaptic plasticity. These results in conjunction with our previous observations of TC LTD in the ACx (Blundon et al., 2011) argue that bidirectional plasticity at TC synapses does not disappear in adults as has been previously suggested and therefore should remain among possible candidates for cellular substrates of experience-dependent cortical map plasticity in sensory cortices.

It is now well accepted that LTP is readily induced at TC synapses by electrical stimulation of the TR in neonatal animals but not in adults (Crair and Malenka, 1995; Kirkwood et al., 1995; Isaac et al., 1997; Feldman et al., 1998; Barth and Malenka, 2001; Foeller and Feldman, 2004; Daw et al., 2007b; Jiang et al., 2007). We determined that this developmental decrease in LTP capability is not attributable to disappearance of plasticity mechanisms at TC synapses and showed that LTP can be unmasked at TC synapses long after the critical period. We demonstrated that electrical stimulations of the TR or optogenetic activation of thalamic projection induces LTP at mature TC synapses in the ACx only if paired with cortical disinhibition and activation of cholinergic inputs from the NB. In our present and previous works (Blundon et al., 2011), we determined that the cholinergic mechanism required for TC LTD and LTP in mature animal is mediated through $\mathrm{M}_{1} \mathrm{Rs}$.

We determined that, in TC synapses, LTP is gated not only by $\mathrm{M}_{1} \mathrm{R}$-dependent mechanisms but also by cortical inhibition. Our experiments showed that these two mechanisms are independent of each other. Absence of either $M_{1} R$ activation or cortical disinhibition deems TC LTP to fail. Although $M_{1}$ Rs activation is a common gating mechanism for both TC LTP and TC LTD, $\mathrm{GABA}_{\mathrm{A}}$ disinhibition is required for TC LTP but not for TC LTD (Blundon et al., 2011). Because in live animals TC LTP may be induced far beyond the early critical period (Lee and Ebner, 1992; Heynen and Bear, 2001; Dringenberg et al., 2004, 2007; Hogsden and Dringenberg, 2009), the requirement of cortical disinhibition for TC LTP in slices may reflect a difference in the inhibitory tone between brain slices and the intact brain. Alternatively, cortical disinhibition can serve as an active synaptic gate for sensory information of increased significance to produce a stronger excitatory output in the thalamorecipient neurons in the ACx. Previous work in vivo revealed that pairing a tone with electrical stimulation of the NB produced a rapid reduction of synaptic inhibition followed by a long-lasting increase in synaptic excitation in the rat ACx (Froemke et al., 2007). This restricted period of activity-dependent cortical disinhibition was proposed to be a "memory trace" of cortical plasticity (Thompson, 2005; Froemke et al., 2007). Cortical disinhibition uncouples the balance of excitation and inhibition that is efficiently maintained in thalamorecipient neurons during TC transmission through feedforward inhibition mechanisms (Wehr and Zador, 2003; Gabernet et al., 
2005) and thus may provide a temporal window for LTP to occur at TC excitatory synapses. A recent attempt to decipher the disinhibitory circuits in the ACx revealed a circuitry that consists of layer I and parvalbumin-positive layer II/III fastspiking interneurons (Letzkus et al., 2011). Maturation of fast-spiking interneurons temporarily coincides with the end of the early critical period for TC synaptic plasticity (Kirkwood and Bear, 1994a; Hensch et al., 1998; Daw et al., 2007a) and therefore may be a good candidate for one component of the LTP gating mechanism. The fast-forward inhibitory circuitry restricts the time window for synaptic integration during TC synaptic transmission (Gabernet et al., 2005) and presumably may use the same mechanism to gate induction of TC LTP. It is not clear why cortical disinhibition is required only for TC LTP but not for TC LTD. Presumably, both forms of TC synaptic plasticity are required for bidirectional cortical map plasticity, during which the cortical area that responds to a conditioning tone is enlarged, whereas the representation of unrelated tone frequencies contracts. There is little doubt that the cortical map enlargement requires an active LTP-like process at synaptic inputs responding to conditioning frequencies. However, coincidental cortical map shrinking may reflect either an active LTD-like process at synaptic inputs responding to nonconditioning frequencies or a consequence of a zero-sum process in which the relative contribution of unconditioned inputs decreases. TC LTD could therefore underlie a form of cortical map plasticity completely independent of TC LTP. Indeed, a recent study indicates that cortical responses in the ACx to identical auditory stimuli may be either potentiated or depressed depending on the sign of the learned behavioral response (to approach and be rewarded vs to avoid or be punished) (David et al., 2012).

The role of TC synapses in cortical plasticity was put in doubt by a work by Froemke et al. (2007) in which MGvevoked EPSCs recorded in vivo failed to change after induction of cortical plasticity in the ACx induced by pairing of a conditioning sound with the electrical stimulation of the NB. In these experiments, Froemke at al. recorded from neurons distributed through several cortical layers (400-1100 $\mu \mathrm{m}$ from the pial surface). Although neurons in multiple cortical layers in the $\mathrm{ACx}$ may respond to a sound, not all of these neurons receive monosynaptic inputs from the MGv. Among neurons that receive monosynaptic MGv inputs, there is little evidence that properties
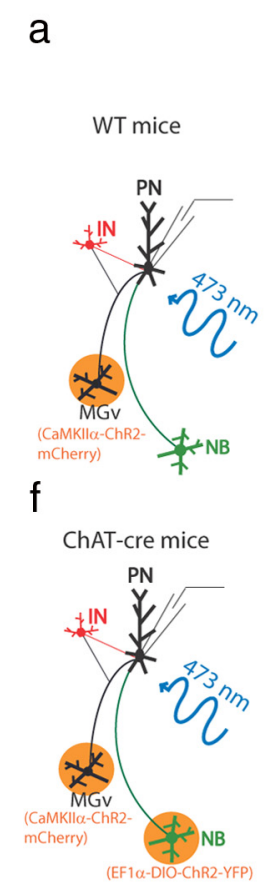
interneuron.
P42-P56
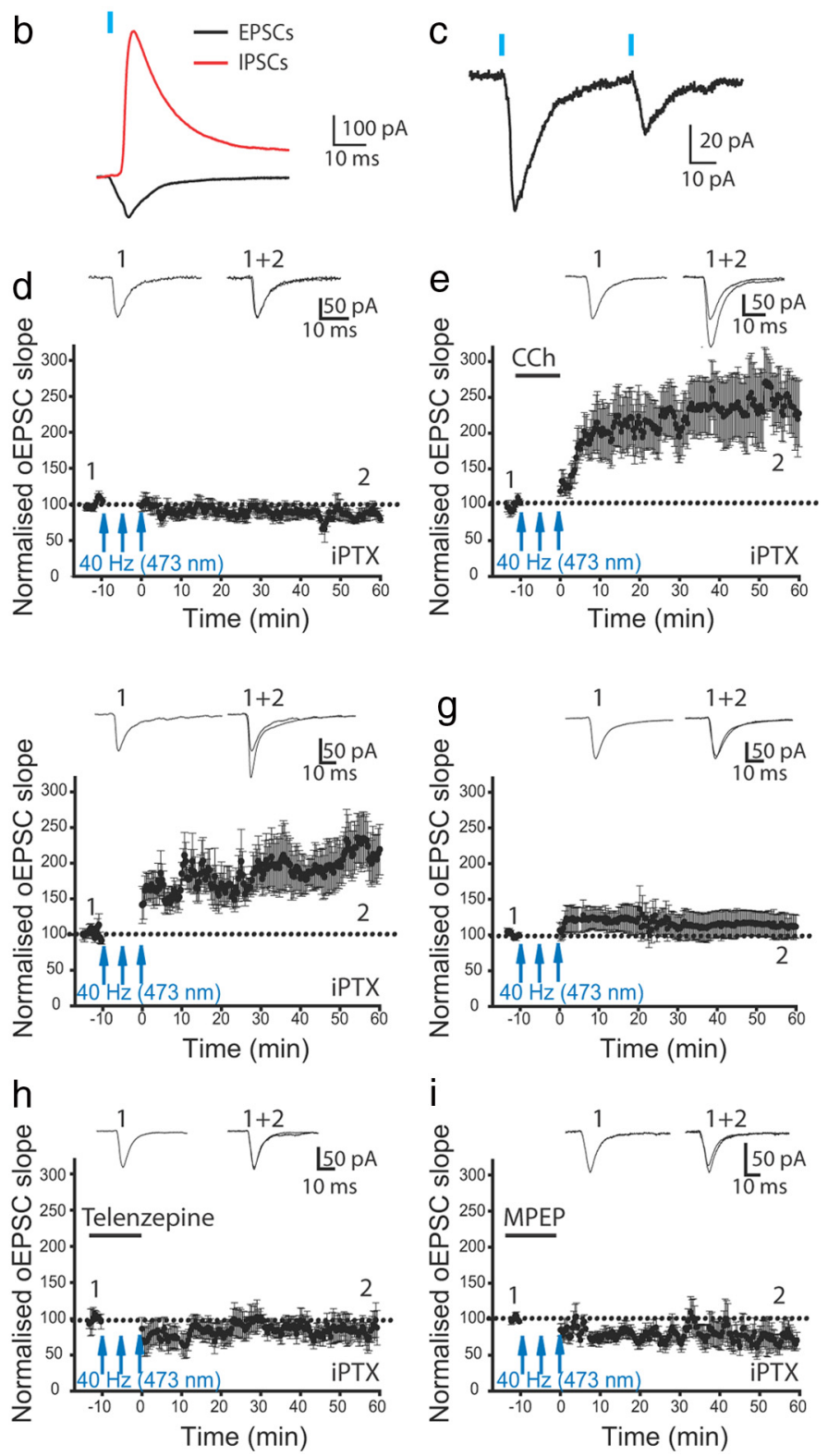

Figure 9. TC LTP is gated by two independent mechanisms. a, Optogenetic stimulation of ChR2-expressing MGv excitatory neurons activates TC synapses. Diagram representing the TC circuitry with MGv excitatory neurons expressing ChR2. $\boldsymbol{b}$, Representative oEPSC and oIPSC evoked optogenetically. c, Paired-pulse depression of oEPSCs is characteristic of TC synapses. Blue bar represents the occurrence of the $1 \mathrm{~ms}, 473 \mathrm{~nm}$ light pulse. $d$, Optogenetic tetanization of TC projections is not sufficient to induce

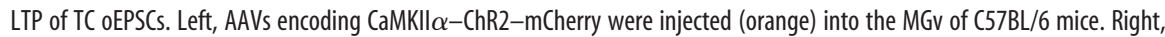
Optogenetically evoked ( $473 \mathrm{~nm}$ ) 0 EPSC as a function of time before and after a $40 \mathrm{~Hz}$ train of $473 \mathrm{~nm}$ light pulses delivered to layer III/IV pyramidal neurons in the presence of iPTX. e, Pairing of $40 \mathrm{~Hz}$ optogenetic tetanization with bath-applied CCh in the presence of iPTX is sufficient to induce TC LTP.f, Left, AAVs encoding CaMKIl $\alpha$-ChR2-mCherry and EF1a-DI0-ChR2-eYFP were injected (orange) into the MGv and NB, respectively, of ChAT-cre mice. Right, Optogenetic tetanization at $40 \mathrm{~Hz}$ of glutamatergic and cholinergic projections into the ACX in the presence of iPTX is sufficient to induce TC LTP. $g$, Optogenetic tetanization at $40 \mathrm{~Hz}$ of glutamatergic and cholinergic projections into the ACx in the absence of iPTX fails to induce TC LTP. $\boldsymbol{h}, \boldsymbol{i}$, LTP induced by $40 \mathrm{~Hz}$ optogenetic tetanization of glutamatergic and cholinergic projections into the ACx in the presence of iPTX is blocked by telenzepine (h) or MPEP (i). Horizontal bar indicates bath application of CCh. Arrows depict the $40 \mathrm{~Hz}$ optogenetic induction protocol. Insets show representative oEPSCs recorded before (1) and after (2) $40 \mathrm{~Hz}$ optogenetic tetanization. PN, Pyramidal neuron; IN,

of these inputs are the same as in MGv-LIII/IV synapses. In contrast to in vivo experiments in which spatial control is difficult to achieve, our experiments in slices were well controlled with respect to a postsynaptic target. Therefore, this uncertainty requires 
P42-P56
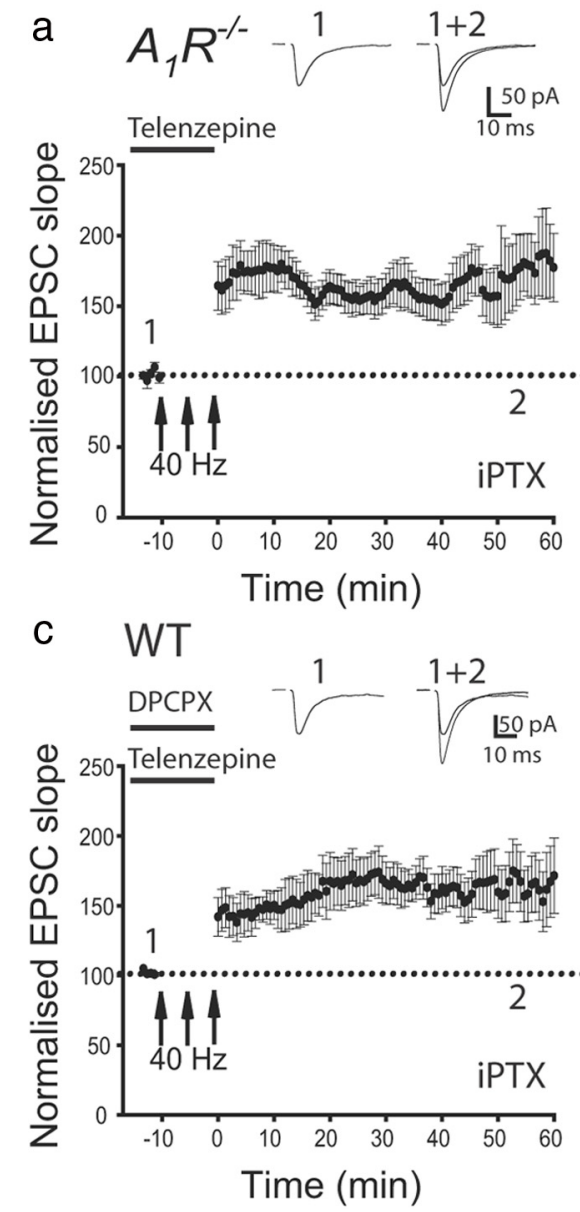

wood and Bear, 1994b; Dudek and Friedlander, 1996; Feldman et al., 1998, 1999). It is not clear why the TC synapses in the ACx use a different postsynaptic mechanism for synaptic plasticity. Nonetheless, these data add another feature to a list of morphologic and functional differences that set the ACx apart from other sensory cortices (King and Nelken, 2009).

We also determined that electrical stimulation of the white matter containing the TR cannot accurately model activation of TC projections during delivery of sensory information to the sensory cortices in vivo. Whereas a single electrical stimulation or a train of low-frequency stimulations preferentially activate TC projections (Blundon et al., 2011), highfrequency trains that we used for LTP induction also involve other projections that enter the ACx through the TR. As we show here, the TR contains not only TC projections but also long-range cholinergic projections from the NB. These cholinergic projections densely innervate the $\mathrm{ACx}$ and also provide a cellular basis for presynaptic gating of synaptic plasticity at TC synapses. Advances in optogenetic methods now allow for specific activation of defined subsets of neurons and thus for more accurate modeling of sensory information processing. Using an optogenetic approach, we found that exclusive tetanization of TC projections causes LTP in mature animals only in the presence of cortical disinhibition and activation of $M_{1}$ Rs. We determined that these two gating mechanisms are independent of each other. Indeed, the release of a single gating mechanism is not sufficient to produce TC LTP. Currently, it is not clear whether these two gating mechanisms emerge confunction of time before and after $40 \mathrm{~Hz}$ ( $\boldsymbol{a}$ ) or $200 \mathrm{~Hz}$ ( $\boldsymbol{b}$ ) electrical tetanization of the TR in slices from $A_{7} R^{-1-}$ mice in the presence of telenzepine and iPTX. $c$, Mean EPSC slopes as a function of time before and after $40 \mathrm{~Hz}$ electrical tetanization of the TR in slices from wild-type mice in the presence of DPCPX, telenzepine, and iPTX. $\boldsymbol{d}$, Mean oEPSC slopes as a function of time after $40 \mathrm{~Hz}$ optogenetic stimulation of TC projections in the presence of telenzepine and IPTX in slices from $A_{7} R^{-/-}$mice. Horizontal bars indicate bath application of telenzepine or DPCPX. Insets show representative EPSCS or oEPSCs recorded before (1) and after (2) application of the electrical or optogenetic induction protocol.

additional evidence to rule out or to confirm a role of TC synaptic plasticity in mechanisms of cortical plasticity. If TC synaptic plasticity contributes to cortical plasticity, it is crucial to understand not only the molecular mechanisms of its gating but also the mechanisms of its expression. Our data indicate that TC LTP in the ACx is expressed postsynaptically. TC LTP is induced at postsynaptic dendritic spines via activation of group I mGluRs and subsequent elevation of postsynaptic calcium. This type of LTP was described previously for other central synapses (Dudman et al., 2007; Cho et al., 2012). Activation of mGluRs may involve voltage-dependent mechanisms that control intracellular calcium in neurons (Bianchi et al., 1999; Power and Sah, 2005). Therefore, it is possible that mGluR activation and cortical disinhibition work synergistically to induce TC LTP in dendritic spines of thalamorecipient neurons. Interestingly, in contrast to the ACx, TC LTP in somatosensory or visual cortices depends on NMDARs (Crair and Malenka, 1995; Barth and Malenka, 2001; Heynen and Bear, 2001; Gagolewicz and Dringenberg, 2011). We also observed a similar discrepancy for TC LTD: whereas TC LTD in the ACx depends on group I mGluRs (Blundon et al., 2011), TC LTD in other sensory cortices is NMDAR dependent (Kirk- comitantly at or near the conclusion of the early critical period. Because these two mechanisms work independently, maturation of either cortical inhibition or $\mathrm{M}_{1} \mathrm{R}$ suppression of adenosine signaling alone could be sufficient to gate TC LTP in adults.

In conclusion, in this work, we show that TC synapses in slices from mature animals do not lose the capacity for LTP with age. Rather TC synapses acquire gating mechanisms that mask TC LTP after the early critical period. In conjunction with our previous study, we show that TC LTP and TC LTD (Blundon et al., 2011) are gated by presynaptic cholinergic mechanisms. Similar to experience-dependent cortical map plasticity in the ACx of adults, these cholinergic mechanisms involve activation of projections from the $\mathrm{NB}$ and activation of $\mathrm{M}_{1}$ Rs. In our present and previous works, we describe that $M_{1}$ Rs on thalamic projections to the $\mathrm{ACx}$ negatively regulate presynaptic adenosine signaling through $A_{1}$ Rs and thus maintain sustained neurotransmitter release from thalamic terminals (Blundon et al., 2011). Deletion of $A_{1}$ Rs bypasses the cholinergic requirement for both TC LTP and TC LTD (Blundon et al., 2011). These data imply that synaptic plasticity at TC projections may contribute to experience- 
dependent cortical map plasticity in the ACx and suggest a role of adenosine signaling in these mechanisms.

\section{References}

Artola A, Singer W (1987) Long-term potentiation and NMDA receptors in rat visual cortex. Nature 330:649-652. CrossRef Medline

Bakin JS, Weinberger NM (1990) Classical conditioning induces CSspecific receptive field plasticity in the auditory cortex of the guinea pig. Brain Res 536:271-286. CrossRef Medline

Bakin JS, Weinberger NM (1996) Induction of a physiological memory in the cerebral cortex by stimulation of the nucleus basalis. Proc Natl Acad Sci U S A 93:11219-11224. CrossRef Medline

Bao S, Chan VT, Merzenich MM (2001) Cortical remodelling induced by activity of ventral tegmental dopamine neurons. Nature 412: 79-83. CrossRef Medline

Barth AL, Malenka RC (2001) NMDAR EPSC kinetics do not regulate the critical period for LTP at thalamocortical synapses. Nat Neurosci 4:235236. CrossRef Medline

Beierlein M, Connors BW (2002) Short-term dynamics of thalamocortical and intracortical synapses onto layer 6 neurons in neocortex. J Neurophysiol 88:1924-1932. Medline

Bianchi R, Young SR, Wong RK (1999) Group I mGluR activation causes voltage-dependent and -independent $\mathrm{Ca}^{2+}$ rises in hippocampal pyramidal cells. J Neurophysiol 81:2903-2913. Medline

Bieszczad KM, Weinberger NM (2010) Representational gain in cortical area underlies increase of memory strength. Proc Natl Acad Sci U S A 107:3793-3798. CrossRef Medline

Blundon JA, Zakharenko SS (2008) Dissecting the components of longterm potentiation. Neuroscientist 14:598-608. CrossRef Medline

Blundon JA, Bayazitov IT, Zakharenko SS (2011) Presynaptic gating of postsynaptically expressed plasticity at mature thalamocortical synapses. J Neurosci 31:16012-16025. CrossRef Medline

Boyden ES, Zhang F, Bamberg E, Nagel G, Deisseroth K (2005) Millisecondtimescale, genetically targeted optical control of neural activity. Nat Neurosci 8:1263-1268. CrossRef Medline

Buonomano DV, Merzenich MM (1998) Cortical plasticity: from synapses to maps. Annu Rev Neurosci 21:149-186. CrossRef Medline

Cetin A, Komai S, Eliava M, Seeburg PH, Osten P (2006) Stereotaxic gene delivery in the rodent brain. Nat Protoc 1:3166-3173. CrossRef Medline

Cho JH, Bayazitov IT, Meloni EG, Myers KM, Carlezon WA Jr, Zakharenko SS, Bolshakov VY (2012) Coactivation of thalamic and cortical pathways induces input timing-dependent plasticity in amygdala. Nat Neurosci 15:113-122. CrossRef Medline

Cooke SF, Bear MF (2010) Visual experience induces long-term potentiation in the primary visual cortex. J Neurosci 30:16304-16313. CrossRef Medline

Crair MC, Malenka RC (1995) A critical period for long-term potentiation at thalamocortical synapses. Nature 375:325-328. CrossRef Medline

Cruikshank SJ, Rose HJ, Metherate R (2002) Auditory thalamocortical synaptic transmission in vitro. J Neurophysiol 87:361-384. Medline

Dahmen JC, King AJ (2007) Learning to hear: plasticity of auditory cortical processing. Curr Opin Neurobiol 17:456-464. CrossRef Medline

David SV, Fritz JB, Shamma SA (2012) Task reward structure shapes rapid receptive field plasticity in auditory cortex. Proc Natl Acad Sci U S A 109:2144-2149. CrossRef Medline

Daw MI, Ashby MC, Isaac JT (2007a) Coordinated developmental recruitment of latent fast spiking interneurons in layer IV barrel cortex. Nat Neurosci 10:453-461. CrossRef Medline

Daw MI, Scott HL, Isaac JT (2007b) Developmental synaptic plasticity at the thalamocortical input to barrel cortex: mechanisms and roles. Mol Cell Neurosci 34:493-502. CrossRef Medline

de Villers-Sidani E, Chang EF, Bao S, Merzenich MM (2007) Critical period window for spectral tuning defined in the primary auditory cortex (A1) in the rat. J Neurosci 27:180-189. CrossRef Medline

Dorrn AL, Yuan K, Barker AJ, Schreiner CE, Froemke RC (2010) Developmental sensory experience balances cortical excitation and inhibition. Nature 465:932-936. CrossRef Medline

Dringenberg HC, Kuo MC, Tomaszek S (2004) Stabilization of thalamocortical long-term potentiation by the amygdala: cholinergic and transcription-dependent mechanisms. Eur J Neurosci 20:557-565. CrossRef Medline

Dringenberg HC, Hamze B, Wilson A, Speechley W, Kuo MC (2007) Het- erosynaptic facilitation of in vivo thalamocortical long-term potentiation in the adult rat visual cortex by acetylcholine. Cereb Cortex 17:839-848. CrossRef Medline

Dudek SM, Friedlander MJ (1996) Developmental down-regulation of LTD in cortical layer IV and its independence of modulation by inhibition. Neuron 16:1097-1106. CrossRef Medline

Dudman JT, Tsay D, Siegelbaum SA (2007) A role for synaptic inputs at distal dendrites: instructive signals for hippocampal long-term plasticity. Neuron 56:866-879. CrossRef Medline

Fahle M (2009) Perceptual learning and sensomotor flexibility: cortical plasticity under attentional control? Philos Trans R Soc Lond B Biol Sci 364:313-319. CrossRef Medline

Feldman DE, Brecht M (2005) Map plasticity in somatosensory cortex. Science 310:810-815. CrossRef Medline

Feldman DE, Nicoll RA, Malenka RC, Isaac JT (1998) Long-term depression at thalamocortical synapses in developing rat somatosensory cortex. Neuron 21:347-357. CrossRef Medline

Feldman DE, Nicoll RA, Malenka RC (1999) Synaptic plasticity at thalamocortical synapses in developing rat somatosensory cortex: LTP, LTD, and silent synapses. J Neurobiol 41:92-101. CrossRef Medline

Feldman ML, Peters A (1978) The forms of non-pyramidal neurons in the visual cortex of the rat. J Comp Neurol 179:761-793. CrossRef Medline

Foeller E, Feldman DE (2004) Synaptic basis for developmental plasticity in somatosensory cortex. Curr Opin Neurobiol 14:89-95. CrossRef Medline

Fox K (2002) Anatomical pathways and molecular mechanisms for plasticity in the barrel cortex. Neuroscience 111:799-814. CrossRef Medline

Fritz J, Shamma S, Elhilali M, Klein D (2003) Rapid task-related plasticity of spectrotemporal receptive fields in primary auditory cortex. Nat Neurosci 6:1216-1223. CrossRef Medline

Froemke RC, Merzenich MM, Schreiner CE (2007) A synaptic memory trace for cortical receptive field plasticity. Nature 450:425-429. CrossRef Medline

Gabernet L, Jadhav SP, Feldman DE, Carandini M, Scanziani M (2005) Somatosensory integration controlled by dynamic thalamocortical feedforward inhibition. Neuron 48:315-327. CrossRef Medline

Gagolewicz PJ, Dringenberg HC (2011) NR2B-subunit dependent facilitation of long-term potentiation in primary visual cortex following visual discrimination training of adult rats. Eur J Neurosci 34:1222-1229. CrossRef Medline

Gilbert CD (1998) Adult cortical dynamics. Physiol Rev 78:467-485. Medline

Gilbert CD, Sigman M, Crist RE (2001) The neural basis of perceptual learning. Neuron 31:681-697. CrossRef Medline

Grover LM, Teyler TJ (1990) Two components of long-term potentiation induced by different patterns of afferent activation. Nature 347:477-479. CrossRef Medline

Gunaydin LA, Yizhar O, Berndt A, Sohal VS, Deisseroth K, Hegemann P (2010) Ultrafast optogenetic control. Nat Neurosci 13:387-392. CrossRef Medline

Hensch TK, Fagiolini M, Mataga N, Stryker MP, Baekkeskov S, Kash SF (1998) Local GABA circuit control of experience-dependent plasticity in developing visual cortex. Science 282:1504-1508. CrossRef Medline

Heynen AJ, Bear MF (2001) Long-term potentiation of thalamocortical transmission in the adult visual cortex in vivo. J Neurosci 21:9801-9813. Medline

Hogsden JL, Dringenberg HC (2009) NR2B subunit-dependent long-term potentiation enhancement in the rat cortical auditory system in vivo following masking of patterned auditory input by white noise exposure during early postnatal life. Eur J Neurosci 30:376-384. CrossRef Medline

Inomata N, Tokutomi N, Oyama Y, Akaike N (1988) Intracellular picrotoxin blocks pentobarbital-gated $\mathrm{Cl}-$ conductance. Neurosci Res 6:7275. CrossRef Medline

Insanally MN, Köver H, Kim H, Bao S (2009) Feature-dependent sensitive periods in the development of complex sound representation. J Neurosci 29:5456-5462. CrossRef Medline

Isaac JT, Crair MC, Nicoll RA, Malenka RC (1997) Silent synapses during development of thalamocortical inputs. Neuron 18:269-280. CrossRef Medline

Jiang B, Treviño M, Kirkwood A (2007) Sequential development of longterm potentiation and depression in different layers of the mouse visual cortex. J Neurosci 27:9648-9652. CrossRef Medline

Johansson B, Halldner L, Dunwiddie TV, Masino SA, Poelchen W, Giménez- 
Llort L, Escorihuela RM, Fernández-Teruel A, Wiesenfeld-Hallin Z, Xu XJ, Hårdemark A, Betsholtz C, Herlenius E, Fredholm BB (2001) Hyperalgesia, anxiety, and decreased hypoxic neuroprotection in mice lacking the adenosine A1 receptor. Proc Natl Acad Sci U S A 98:9407-9412. CrossRef Medline

Kantevari S, Matsuzaki M, Kanemoto Y, Kasai H, Ellis-Davies GC (2010) Two-color, two-photon uncaging of glutamate and GABA. Nat Methods 7:123-125. CrossRef Medline

Kawai H, Lazar R, Metherate R (2007) Nicotinic control of axon excitability regulates thalamocortical transmission. Nat Neurosci 10:1168-1175. CrossRef Medline

Keuroghlian AS, Knudsen EI (2007) Adaptive auditory plasticity in developing and adult animals. Prog Neurobiol 82:109-121. CrossRef Medline

Kilgard MP, Merzenich MM (1998) Cortical map reorganization enabled by nucleus basalis activity. Science 279:1714-1718. CrossRef Medline

King AJ, Nelken I (2009) Unraveling the principles of auditory cortical processing: can we learn from the visual system? Nat Neurosci 12:698-701. CrossRef Medline

Kirkwood A, Bear MF (1994a) Hebbian synapses in visual cortex. J Neurosci 14:1634-1645. Medline

Kirkwood A, Bear MF (1994b) Homosynaptic long-term depression in the visual cortex. J Neurosci 14:3404-3412. Medline

Kirkwood A, Lee HK, Bear MF (1995) Co-regulation of long-term potentiation and experience-dependent synaptic plasticity in visual cortex by age and experience. Nature 375:328-331. CrossRef Medline

Lee SM, Ebner FF (1992) Induction of high frequency activity in the somatosensory thalamus of rats in vivo results in long-term potentiation of responses in SI cortex. Exp Brain Res 90:253-261. CrossRef Medline

Letzkus JJ, Wolff SB, Meyer EM, Tovote P, Courtin J, Herry C, Lüthi A (2011) A disinhibitory microcircuit for associative fear learning in the auditory cortex. Nature 480:331-335. CrossRef Medline

Lund JS (1973) Organization of neurons in the visual cortex, area 17, of the monkey (Macaca mulatta). J Comp Neurol 147:455-496. CrossRef Medline

Ma X, Suga N (2003) Augmentation of plasticity of the central auditory system by the basal forebrain and/or somatosensory cortex. J Neurophysiol 89:90-103. Medline

Ma X, Suga N (2005) Long-term cortical plasticity evoked by electric stimulation and acetylcholine applied to the auditory cortex. Proc Natl Acad Sci U S A 102:9335-9340. CrossRef Medline

Massaux A, Dutrieux G, Cotillon-Williams N, Manunta Y, Edeline JM (2004) Auditory thalamus bursts in anesthetized and non-anesthetized states: contribution to functional properties. J Neurophysiol 91:2117-2134. CrossRef Medline

Matsuzaki M, Ellis-Davies GC, Nemoto T, Miyashita Y, Iino M, Kasai H (2001) Dendritic spine geometry is critical for AMPA receptor expression in hippocampal CA1 pyramidal neurons. Nat Neurosci 4:1086-1092. CrossRef Medline

Metherate R, Ashe JH (1993) Ionic flux contributions to neocortical slow waves and nucleus basalis-mediated activation: whole-cell recordings in vivo. J Neurosci 13:5312-5323. Medline

Nelson S, Toth L, Sheth B, Sur M (1994) Orientation selectivity of cortical neurons during intracellular blockade of inhibition. Science 265:774-777. CrossRef Medline

Polley DB, Chen-Bee CH, Frostig RD (1999) Two directions of plasticity in the sensory-deprived adult cortex. Neuron 24:623-637. CrossRef Medline

Polley DB, Heiser MA, Blake DT, Schreiner CE, Merzenich MM (2004) Associative learning shapes the neural code for stimulus magnitude in pri- mary auditory cortex. Proc Natl Acad Sci U S A 101:16351-16356. CrossRef Medline

Polley DB, Steinberg EE, Merzenich MM (2006) Perceptual learning directs auditory cortical map reorganization through top-down influences. J Neurosci 26:4970-4982. CrossRef Medline

Power JM, Sah P (2005) Intracellular calcium store filling by an L-type calcium current in the basolateral amygdala at subthreshold membrane potentials 1. J Physiol 562:439-453. CrossRef Medline

Recanzone GH, Schreiner CE, Merzenich MM (1993) Plasticity in the frequency representation of primary auditory cortex following discrimination training in adult owl monkeys. J Neurosci 13:87-103. Medline

Reed A, Riley J, Carraway R, Carrasco A, Perez C, Jakkamsetti V, Kilgard MP (2011) Cortical map plasticity improves learning but is not necessary for improved performance. Neuron 70:121-131. CrossRef Medline

Richardson RJ, Blundon JA, Bayazitov IT, Zakharenko SS (2009) Connectivity patterns revealed by mapping of active inputs on dendrites of thalamorecipient neurons in the auditory cortex. J Neurosci 29:6406-6417. CrossRef Medline

Roelfsema PR, van Ooyen A, Watanabe T (2010) Perceptual learning rules based on reinforcers and attention. Trends Cogn Sci 14:64-71. CrossRef Medline

Rose HJ, Metherate R (2001) Thalamic stimulation largely elicits orthodromic, rather than antidromic, cortical activation in an auditory thalamocortical slice. Neuroscience 106:331-340. CrossRef Medline

Rutkowski RG, Weinberger NM (2005) Encoding of learned importance of sound by magnitude of representational area in primary auditory cortex. Proc Natl Acad Sci U S A 102:13664-13669. CrossRef Medline

Smith PH, Populin LC (2001) Fundamental differences between the thalamocortical recipient layers of the cat auditory and visual cortices. J Comp Neurol 436:508-519. CrossRef Medline

Suga N, Ma X (2003) Multiparametric corticofugal modulation and plasticity in the auditory system. Nat Rev Neurosci 4:783-794. CrossRef Medline

Thompson RF (2005) In search of memory traces. Annu Rev Psychol 56:123. CrossRef Medline

Wang XF, Daw NW (2003) Long term potentiation varies with layer in rat visual cortex. Brain Res 989:26-34. CrossRef Medline

Wehr M, Zador AM (2003) Balanced inhibition underlies tuning and sharpens spike timing in auditory cortex. Nature 426:442-446. CrossRef Medline

Weinberger NM (1995) Dynamic regulation of receptive fields and maps in the adult sensory cortex. Annu Rev Neurosci 18:129-158. CrossRef Medline

Weinberger NM (2004) Specific long-term memory traces in primary auditory cortex. Nat Rev Neurosci 5:279-290. CrossRef Medline

Weinberger NM (2007) Associative representational plasticity in the auditory cortex: a synthesis of two disciplines. Learn Mem 14:1-16. CrossRef Medline

Yazaki-Sugiyama Y, Kang S, Câteau H, Fukai T, Hensch TK (2009) Bidirectional plasticity in fast-spiking GABA circuits by visual experience. Nature 462:218-221. CrossRef Medline

Zakharenko SS, Zablow L, Siegelbaum SA (2001) Visualization of changes in presynaptic function during long-term synaptic plasticity. Nat Neurosci 4:711-717. CrossRef Medline

Zakharenko SS, Patterson SL, Dragatsis I, Zeitlin SO, Siegelbaum SA, Kandel ER, Morozov A (2003) Presynaptic BDNF required for a presynaptic but not postsynaptic component of LTP at hippocampal CA3-CA1 synapses. Neuron 39:975-990. CrossRef Medline

Zhang LI, Bao S, Merzenich MM (2001) Persistent and specific influences of early acoustic environments on primary auditory cortex. Nat Neurosci 4:1123-1130. CrossRef Medline 